\title{
SHP2 promotes Triple Negative Breast Cancer by mediating crosstalk between EGFR and Wnt beta-catenin signaling pathways
}

Elisha Martin

Follow this and additional works at: https://researchrepository.wvu.edu/etd

\section{Recommended Citation}

Martin, Elisha, "SHP2 promotes Triple Negative Breast Cancer by mediating crosstalk between EGFR and Wnt beta-catenin signaling pathways" (2016). Graduate Theses, Dissertations, and Problem Reports. 6168.

https://researchrepository.wvu.edu/etd/6168

This Thesis is protected by copyright and/or related rights. It has been brought to you by the The Research Repository @ WVU with permission from the rights-holder(s). You are free to use this Thesis in any way that is permitted by the copyright and related rights legislation that applies to your use. For other uses you must obtain permission from the rights-holder(s) directly, unless additional rights are indicated by a Creative Commons license in the record and/ or on the work itself. This Thesis has been accepted for inclusion in WVU Graduate Theses, Dissertations, and Problem Reports collection by an authorized administrator of The Research Repository @ WVU. For more information, please contact researchrepository@mail.wvu.edu. 


\title{
SHP2 promotes Triple Negative Breast Cancer by mediating crosstalk between EGFR and Wnt/ $\beta$-catenin signaling pathways
}

\author{
Elisha Martin
}

Thesis submitted to the School of Medicine at West Virginia University in partial fulfillment of the requirements for the degree for

\author{
Master of Science \\ In \\ Biomedical Science \\ Yehenew Agazie, Ph.D., Chair \\ Michael Schaller Ph.D. \\ Alexey Ivanov Ph.D. \\ Heimo Riedel Ph. D. \\ Department of Biomedical Sciences \\ Morgantown, West Virginia \\ 2016
}

Key words: SHP2 Basal-like and Triple Negative Breast Cancer, EGFR, $\beta$-catenin, Biomedical Sciences

Copyright of 2016, Elisha Martin 


\section{ABSTRACT \\ SHP2 promotes Triple Negative Breast Cancer by mediating crosstalk between EGFR and Wnt/ $\beta$-catenin signaling pathways}

\section{Elisha Martin}

Basel-like/ Triple Negative Breast Cancer (BTBC) are a subtype of Breast Cancer that are clinically characterized as an aggressive and highly metastatic disease phenotype and poor outcome for women who are diagnosed with this disease. Patients with BTBCs lack treatment options for target therapeutics that are available for other Breast Cancer subtypes (e.g. tamoxifen and herceptin) and have been shown to have a disproportional mortality rate in minority and in young woman of all races. The need to find and characterize a potential therapeutic target for BTBC is an exterimal important focus for many researcher laboratories. Src-homology phosphotyrosyl phosphatase 2 (SHP2) could potentially be therapeutic target for BTBC, for the reason it's an essential mediator of Receptor Tyrosine Kinases (RTKs), which are dysregulated in BTBC such as Epidermal Growth Factor Receptor (EGFR), c-Met, Fibroblast Growth Factor Receptor (FGFR) and ect. Here, we show that silencing of SHP2 in BTBC leads to a reduction in cell proliferation, transformation and a loss of a cancer stem cells phenotype. Furthermore, silencing of SHP2 in BTBC leads to a loss of basal and ligand stimulation signaling downstream to PI3k/AKT and MAPK/ERK1/2 pathways form RTK and RTK expression. We also show that silencing of SHP 2 causes a reduction in $\beta$-catenin proteins, loss of $\beta$-catenin target gene expression and loss of nuclear localization. Silencing of $\beta$-catenin in BTBC also showed a reduction in cell proliferation, transformation, loss of EGFR protein and mRNA expression along with a reduction in SHP2 protein levels. Taken together, these observations suggest that SHP2 is essential for RTK signaling, expression and $\beta$-catenin proteins stability which is need for expression of RTKs in BTBC, showing that SHP2 can be a potential therapeutic target for BTBC treatment. 


\section{ACKNOWLEDGMENTS}

I would like to express my deepest appreciation to Dr. Yehenew Agazie, for his inspiration, guidance, and support during my studies. The time that he spent mentoring me is one that I will never forget and I thank him for all of his teaching and how to be a scientist. I would also like to thank the members of my committee, Dr. Alexey Ivanov, Dr. Heimo Riedel, and Dr. Micheal D. Schaller for their advice and support throughout my studies. I would like to thank the whole Biochemistry department faculty, staff and graduate students for their help throughout my studies; they help to make the time that I was here a fun and education experience that I will never forget. 


\section{Table of contents}

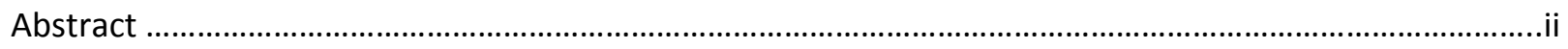

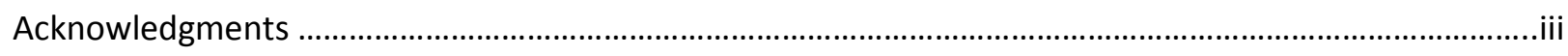

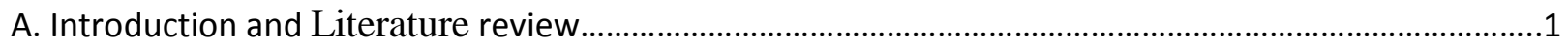

A.1 Epidemology

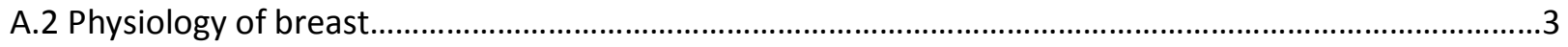

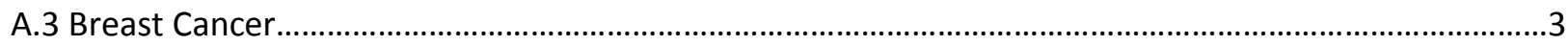

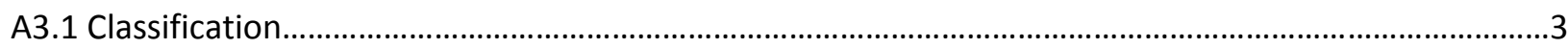

A3.2 Basal-like and triple-negative breast cancer................................................................................

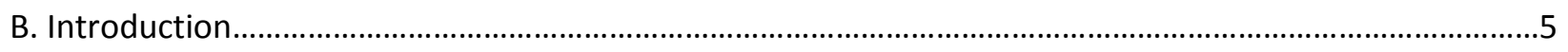

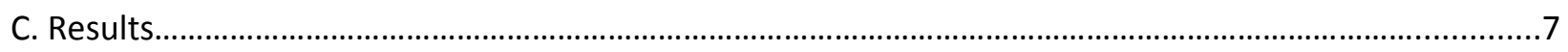

C.1 SHP2 is important for basal signaling and mescnchymal growth properties in BTBC cells.....................7

C.2 SHP2 us essential for cell proliferation, anchorage-indepedet growth, and cancer stem cell

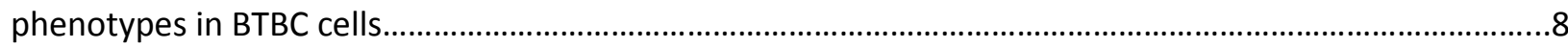

C.3 SHp2 is essential for expression and signaling by multiple RTKs in BTBC cells.................................. 10

C.4 SHP2 regulates the expression of $\beta$-catenin and its transcriptional targets in BTBC cells.................... 11

C. $5 \beta$-catenin is essential for the growth and transformation if BTBC cells............................................ 12

C. $6 \beta$-catenin is directly involved in transcription of EGFR...................................................................13

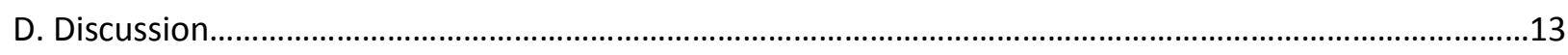

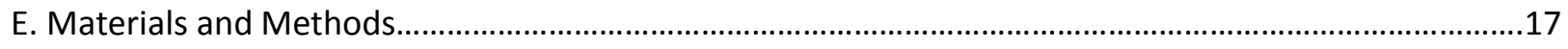

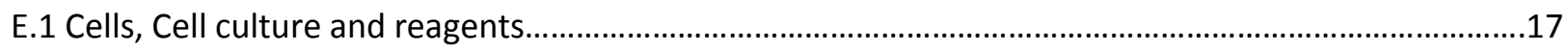

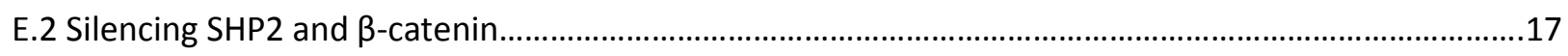

E.3 Cell lysates, Immunoblotting, and cytoplasmic-nuclear fraction analyzes..................................... 18

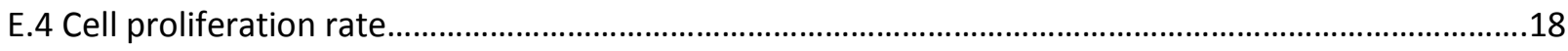

E.5 Proteasome inhibition and EGF, FGF and HGF stimulation............................................................19

E.6 Anchorage-independent growth assay and Mammosphere formation assay................................. 19

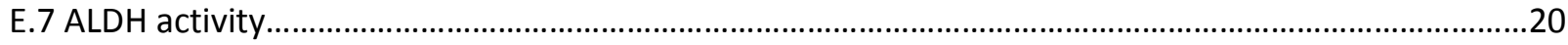




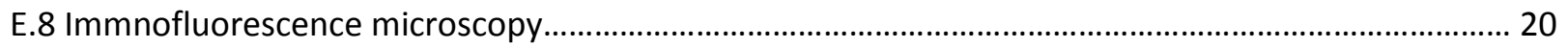

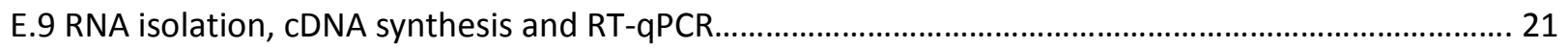

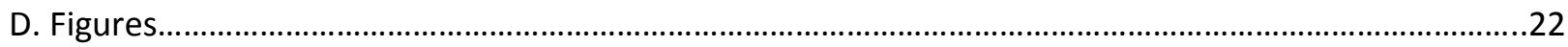

D.1 Figure 1. Silencing of SHP2 in BTBC leads to reduction in transformation and basal signaling............ 22

D.2 figure 2. Effect of SHP2 silencing on cells proliferation, transformation and CSC population in

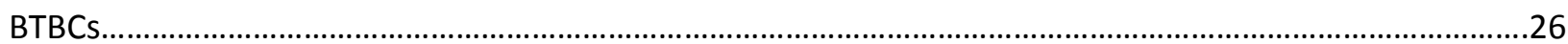

D.3 Figure 3. Silencing of SHP2 leads to a loss of signaling and expression of multiple RTKs in BTBCs....28

D.4 figure 4. SHP2 promotes mRNA expression of EGFR in BTBCs.............................................................

D.5 Figure 5. EGFR is a transcriptional target of $\beta$-catenin in BTBCs........................................................33

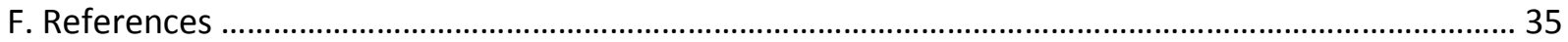




\section{A. Literature Review}

\section{A1. Epidemiology}

Breast cancer (BC) is the second leading cause of death for women worldwide. BC also affects men, but at a relatively very low rate. In 2012 alone, there were an estimated 1.7 million new cases and 522,000 deaths of BC. When it comes to the United States, the incidence is even higher with an estimated 234,190 new cases and 40,730 deaths in 2015 alone. Multiple factors are known to be risk factors for BC development. These include, environment, life style, racial differences, age, age of giving the first birth, number of births, age of menarche and menopause, diet, alcohol and tobacco use, hormone replacement therapies, family history, and obesity.

Developed countries have a higher trend for breast cancer incidence. One suggested reason for this has been difference in life style of women in developed versus developing countries. For instance, frequent consumption of processed food, which is heavily used in developed countries, is known to increase BC and other cancer risks both in women and men [1] Other reasons for this difference are suggested to be industrial toxins and environmental prolusion $[2,3]$.

Women of different racial and economical backgrounds are affected differentially by BC in terms of percentage of women diagnosed, survival rate and treatment options. For instance, the incidence rate of $\mathrm{BC}$ in the United States is higher among White non-hispanic women with 127.6 per 100,000 followed by African American women with 123 per 100, 000. This rate is much lower in Asian American and Pacific Islander women with 86 per 100,000 [4] . However, African American

women have the highest mortality rate compared to other ethnic groups in the United States with a mortality rate of 31.4 per 100,000, followed by White non-Hispanic women with 22.2 per 100,000. One reason for this disproportionality in mortality versus incidence rate is difference in economical standing $[5,6]$. The prevailing poverty and lack of insurance leaves some African American women 
unable to seek proper treatment. There is also information about some doctors withholding information on available therapeutic options because of an individual's inability to pay for treatment [7]. Cultural differences that affect life style particularly diet and alcohol and tobacco use are also known to contribute to differences in $\mathrm{BC}$ incidence rate.

Women who give birth before the age of 30 have a lower chance of getting $\mathrm{BC}$ than those who give birth after 30. Furthermore, women with pregnancies have a lower chance of developing BC. Women who start menstruating before age 12 have a higher risk of $\mathrm{BC}$ when compared to those who start at a later age. With regard to menopausal state, women who lag have a higher risk of BC those who start before age 55[5]. Alcohol use has been shown to increases the risk of a woman to develop BC compared to non-alcohol drinkers. Women who drink alcohol have higher levels of estrogen in their blood than those who don't drink. Smoking is a risk factor that is still under study with data supporting and disclaiming smoking as a risk for $\mathrm{BC}[8,9]$.

Obesity has also been shown to be associated with BC risk. Studies have shown that obesity after menopause leads to increased risk of BC. It is suggested that increased fat tissue in the body leads to increased production of estrogen by adipocytes, leading to increased estrogen signaling that activates proliferation of breast cells [10]. Hormone replacement therapies have been used to relieve symptoms of menopause and to stop osteoporosis. However, reports indicate that such treatments may increase $\mathrm{BC}$ risk due to increased estrogen signaling [11]. This is a possibility since increased estrogen signaling is the cause of hormone-positive breast cancer [12]. Obesity also leads to an increased blood insulin level, which can induce growth of breast cells and cancer development[9] .

Family history of $\mathrm{BC}$ also is considered a risk factor particularly if the patient carries genetically transmissible mutations such as deletion or functional inactivation of the breast cancer susceptibility gene 1 (BRCA1) and to some extent BRCA2 [13].. 


\section{A2. Physiology of the breast}

The physiological role of the breast is milk production as a nutrient for new born babies. During pregnancy, the breast epithelia goes through several rounds of cellular proliferation and differentiation that lead to formation of lobuloalvelar structures and ducts that are connected to the nipple. A fully developed breast is composed of multiple lobes formed by 20 to 40 lobules and ducts that emanate from them. The lobules within each lobe are connected to ducts and collection ducts that lead to the nipple of each breast. These epithelial structures are spread throughout the fatty and fibrous connective tissues that form most of the mass of the breast. The lobes and collection ducts connected the nipple resemble bunches of grapes connected to the stalk of the grape tree. During lactation, milk is produced in the lobules and then carried by the ducts to collection ducts and finally to the nipples. The nipple is surrounded externally by a glandular tissue called areola composed of sweet glands that lubricate the nipple during breast feeding. Inside the breast there are lymph nodes from the lymphatic system located in fatty and fibrous connective tissues along with blood vessels

\section{A3. Breast cancer}

\section{A3.1 Classification}

$\mathrm{BC}$ is broadly classified into three major categories based on state of estrogen receptor (ER), progesterone receptor (PR) and epidermal growth factor receptor 2 (EGFR2), also known as human EGFR2 (HER2), expression. Immunohistochemistry (IHC) is the primary method to classify BC as hormone positive (ER/PR-positive), HER2-positive and triple-negative (negative for ER, PR and HER2 expression). The hormone-positive subtype is identified by expression of the estrogen and progesterone receptors (ER and PR), while the HER2-positive subtype by HER2 overexpression. The subtype lacking ER/PR/HER2 expression is identified as triple-negative. A more recent gene 
expression-based profiling provides five subtypes: luminal A, luminal B, HER2-positive, basal-like and normal-like [14-16].

Luminal-like tumors are characterized by high expression of ER and PR and low rate of p53 mutations. Generally, accumulation of ER in the nucleus of luminal-like tumor cells is considered as a driving factor. Indeed, anti-hormone therapies (anti-estrogen drugs) such as tamoxifen and aromatase inhibitors are effective against these types of tumors. As a result, diagnosis with hormone-positive breast cancer is regarded as good prognosis. The HER2-positive tumors are characterized by overexpression of the HER2 protein due to gene amplification and/or polysomy. HER2 is a constitutively-active receptor tyrosine kinase that can homodimerize or heterodimerize with family members to drive activation of the Ras-extracellular signal regulated kinase 1 and 2 (RAS(ERK1/2) and the phosphatidylinositol-3 kinase and Akt (PI3K-Akt) signaling pathways that are known to promote cancer cell growth and survival. Targeting the function of HER2 with specific drugs such as trastuzumab (herceptin) and the tyrosine kinase inhibitor lapatinib has shown efficacy against these types of tumors. Basel-like tumors constitutes a heterogeneous group of tumors. About $85 \%$ of basallike tumors are triple-negative and exhibit very high rates of p53 mutation and downregulation of breast cancer susceptibility gene 1 and 2 (BRCA-1 and BRCA-2) mutations. Another characteristic feature of basal-like tumors is dysregulation of multiple RTKs, including EGFR, c-MET, FGFR, and IGF-1R [17-23]. Normal breast-like are tumors cluster with normal breast samples in terms of gene expression profile.

\section{A3.2 Basal-like and triple-negative breast cancer}

Although the term triple-negative is not used in this classification, basal-like is often used as a surrogate since approximately $85 \%$ of basal-like tumors are triple-negative and vice versa [24-26]. Hereinafter, the term basal-like and triple-negative breast cancer (BTBC) which satisfies both 
subgroups is used throughout this thesis. The basal-like and triple-negative breast cancer (BTBC) represents approximately $10-15 \%$ of all $\mathrm{BCs}$, but it causes disproportionately high mortalities in women particularly in racial minorities and younger women of all races $[27,28]$. One of the major factors to the poor clinical outcome is the lack of targeted therapy, which is further complicated by the multiplicity of dysregulated molecules that drive tumor growth and metastasis. Many reports show that the commonly dysregulated molecules in BTBC are receptor tyrosine kinases (RTKs) [17-23]. But, inhibition of individual RTKs did not lead to a substantial benefit to BTBC patients [29, 30]. It is therefore imperative to discover and target master-regulators of RTK signaling to overcome the difficulty posed by the multiplicity of dysregulated molecules. Recent reports show that the Src homology phosphotyrosyl phosphatase 2 (SHP2) is a master regulator of RTK signaling in BTBC. But, its mechanism is poorly understood. This thesis work therefore focuses on the role of SHP2 in BTBC.

\section{B. Introduction}

SHP2 is a non-receptor protein tyrosine phospatases that is encoded by the PTPN11 gene on chromosome 12. SHP2 has two Src homology 2(SH2) domains in the N-terminal region and a protein tyrosine phosphatases (PTP) domain in the C-terminal region, and tyrosine phosphorylation sites in $\mathrm{C}$ terminal tail. The tyrosine phosphatase activity of SHP2 is regulated by an intermolecular conformational switch that closes and opens the PTP domain. In the resting state, SHP2 assumes a closed conformation mediated by interaction of the N-terminal SH2 domain with the PTP domain, leading to blockade of substrate binding to the active site. Interaction of the two SH2 domains with phosphotyrosine on interacting partner proteins induces an open conformation that allow substrate binding. Germline mutations that disrupt interaction between the N-SH2 and the PTP domain have been shown to lead to a constitutively active open conformation. SHP2 proteins with gain-of-function 
mutations have been discovered in human disease and are regarded as causes for development of what is known as Noonan Syndrome characterized by facial abnormalities, cardiomyopathies, and increased incidence of hematopoietic malignancies. Increased activation of the Ras-extracellular signal regulated kinase 1 and 2 (Ras-ERK1/2) signaling pathway has been consistently found in patients with Noonan syndrome, suggesting that activation of SHP2 can lead to over-activation of this signaling pathway. Loss-of-function mutations of SHP2 have also been discovered in humans and are known to lead to development of LEOPARD syndrome. Children who harbor these two types of mutations have mental retardation, stunted growth, and death at a young age [31-34]. These findings suggested that SHP2 is needed for normal development in the heart, lungs, breast, and testis [35] and knockouts of SHP2 in mice is embryonic lethal. In addition to mutational activation, increased tyrosine phosphorylation in a cell can also lead to over-activation of SHP2. For instance, overexpression of a virulence factor cytotoxin-associated gene $\mathrm{A}(\mathrm{CagA})$ by Helicobacter pylori in gastric infection leads to over-activation of SHP2 which is cinsidered to be the caus of cancer development [36]. Src family tyrosine kinases have been shown to phosphorylate CagA which in turn interacts with the SH2 domains of SHP2 and activates its enzyme function by inducing an open conformation.

The uniqueness of SHP2 is that its PTPase activity promotes rather than inhibits tyrosine kinase signaling [20, 37-39]. For instance, many receptor tyrosine kinase (RTK) known to date require SHP2 to effectively activate the Ras-ERK1/2 and the phosphatidylinositol-3 kinase -Akt (PI3K-Akt) signaling pathways [17, 19-21, 23, 40-45]. But, the mechanism of SHP2 in mediating RTK signaling is poorly understood. The most daunting problem in understanding the mechanism of SHP2 is the elusiveness of biological substrates. Only a handful publications have attempted to explain the mechanism of action. In EGFR and HER2 signaling, SHP2 mediates sustained Ras activation by blocking the Ras GTPase activating protein (RasGAP) for accessing Ras at the plasma membrane through dephosphorylation of RasGAP docking sites on both receptor molecules [41, 46]. In case of 
FAK, SHP2 acts on pTyr397 to promote turnover of focal adhesions during cell migration [47] and in case of $\alpha$-catenin SHP2 disrupts its interaction with $\beta$-catenin to increase its cytoplasmic pool [19]. Other reports show that SHP2 also promotes Src activation by blocking recruitment of the inhibitory C-terminal Src kinase (Csk) to the plasma membrane [44].

Because RTK overexpression in cancer including BC is commonplace and because SHP2 is a requisite downstream signal transducer, its state of expression was explored in cancer. SHP2 was first reported to be overexpressed in BC both in HER2-positrive and HER2-negative invasive ductal carcinomas by our laboratory [48] which was followed few years later by another group [49]. Since then, our laboratory has shown in multiple publications that SHP2 plays a fundamental role in BC. First, it was demonstrated that inhibition of SHP2 in both HER2-positive and basal-like and triplenegative breast cancer (BTBC) cell lines induces mesenchymal to epithelial transition (MET) [50]. Second, it was shown that SHP2 is essential for cell polarity and migration [51] and extracellular matrix degradation and invasion [52] in BTBC cells. Very interestingly, inhibition of SHP2 in BTBC cells induces basal-to-luminal transition, expression of estrogen receptor alpha (ER $\alpha)$, dependency on estrogen signaling for growth, and sensitivity to anti-estrogen (tamoxifen) therapy. And third, it was demonstrated recently that SHP2 is essential for cell proliferation, transformation, tumorigenic and metastatic property of BTBC cells [53]. However, the mechanism of SHP2 in promoting these phenotypes in breast cancer particularly in BTBC is not understood. In this thesis work, the role and mechanism of SHP2 in BTBC cell growth, transformation, and proto-oncogene expression, and signaling has been investigated.

\section{Results}

\section{C.1 SHP2 is important for basal signaling and mesenchymal growth properties in BTBC cells}


To determine the functional significance of SHP2 in BTBC, we silenced SHP2 expression in two BTBC cell lines, the MDA-MB231 and the MDA-MB468 cells, which harbor multiple genetic changes commonly discovered in BTBC $[54,55]$. These include activating Ras mutation in the MDA-MB231, elevated EGFR expression and p53 mutation in both $[54,56]$, and PTEN homodeletion and EGFR gene amplification in the MDA-MB468 cells [54, 57]. In addition, both cell lines show elevated SHP2 expression [48]. The expression of SHP2 was silenced with two independent shRNAs that were previously shown to be specific and devoid of off-target effects [47, 58]. Cells expressing luciferase shRNA were used as controls in this study. As shown in Fig.1A, immunoblotting (IB) analysis of total cell lysates showed effectively silencing of SHP2 expression by both shRNA constructs (sh-1 and sh-2). Because SHP2 is an essential mediator of mitogenic and cell survival signaling, we determined basal levels of Akt and extracellular signal regulated kinase 1 and 2 (ERK1/2) activation and found a profound inhibition in both cases as assessed by the state of phosphorylation (Fig.1B). These findings suggest that silencing SHP2 suppresses basal signaling in BTBC cells.

Observation of parental, control and SHP2-silenced cells (sh-1 and sh-2) growing in 2D under a microscope showed major morphological differences. When compared to the parental and the controls cells which are mesenchymal, elongated, and interspersed, the SHP2-silenced cells had acquired a flattened epithelial morphology characteristic of luminal epithelial cells (Fig.1C and D). These findings suggest that SHP2 is essential for the maintenance of the mesenchymal phenotype in BTBC cells and its inhibition leads to acquisition of a normal-looking epithelial phenotype.

\section{C.2 SHP2 is essential for cell proliferation, anchorage-independent growth, and cancer stem cell phenotypes in BTBC cells}


Based on the effect of SHP2 inhibition on basal signaling and the mesenchymal growth properties, it was reasoned that SHP2 might also be important for the transformation phenotypes of BTBC cells. First, the effect of SHP2 silencing on cell proliferation rate was determined by direct counting. Equal number of cells were seeded in 2D cultures and the effect of SHP2 silencing on proliferation rate was determined by counting cells as described in the materials and methods section. The results showed that inhibition of SHP2 suppresses cell proliferation. While the parental and control cells proliferated by approximately 10 fold over 3 days, the SHP2-silenced cell grew by only 3-4 fold in the same period of time Fig.2A and B). Thus, SHP2 is essential for BTBC cell proliferation.

Next, the effect of SHP2 silencing on anchorage-independent growth was determined. Equal number of parental, control and SHP2-silenced cells (sh-1 and sh-2) were seeded in soft agar and growth of colonies was monitor by microscopic examination. While the parental and the control cells formed larger and numerous colonies, the SHP2-silenced cells formed smaller and fewer ones (Fig.2C). Counting colony number per $4 \times$ objective showed approximately 22 larger colonies in the parental and control cells, but only 2-4 smaller colonies in the SHP2-silenced cells (Fig.2D). These findings suggested that SHP2 is essential for anchorage-independent growth in BTBC cells.

The inability of the SHP2-silenced cells to grow in soft agar indicated a role for SHP2 in cancer stem cell (CSC) biology. To verify this point, the ability of cells to grow in suspension culture, in the so called mammosphere formation assay, was determined. In this assay, cells with stem-like properties only can survive and form mammospheres (also known as tumorisphere) [59, 60]. Whereas mammosphere-forming efficiency in the parental and the control cells was increased on successive passaging from primary to secondary cultures, it was exhausted in the SHP2-silenced cells (Fig.2E and G). To complement the mammosphere formation data, the effect of SHP2 on aldehyde dehydrogenase 1 (ALDH1) activity, another property of CSCs [61], was determined. To accomplish this task, the Millipore ALDEFLUOR assay kit was utilized. While the control MDA-MB231 cells 
had $4.97 \%$ ALDH1-high cells, the corresponding SHP2-silenced cells had only $0.23 \%$, a more than 20-fold reduction (Fig.2F)). Similar results were obtained with the MDA-MB468 cells except that the proportion of CSCs in this cell line was higher relatively (Fig.2G ). Therefore, SHP2 is important for the maintenance of CSC phenotypes in BTBC cells.

\section{C.3 SHP2 is essential for expression and signaling by multiple RTKs in BTBC cells}

The low level of basal Akt and ERK1/2 activation was indicative of SHP2 regulating signaling by multiple receptor tyrosine kinases (RTKs) that are known to be dysregulated in BTBC. To test this possibility, the effect of SHP2 silencing on signaling by three RTKs, namely EGFR, FGFR1 and cMET, which are commonly dysregulated in BTBC, was studied in a time-course fashion. Control and SHP2-silenced (sh-2) cells were serum starved overnight and then stimulated with $20 \mathrm{ng} / \mathrm{ml}$ EGF, FGF or HGF for varying time points, ranging from 10 minutes to 4 hours, and lysates prepared from them were analyzed for Akt and ERK1/2 by immunoblotting with antibodies that recognized the activated forms. The results showed that Akt and ERK1/2 activation induced by the respective ligands were suboptimal and short-lived in the SHP2-silenced cells, but robust and sustained in the controls (Fig.3A-F). Hence, SHP2 is essential for dysregulated signaling by multiple RTKs in BTBC cells.

Since receptor downregulation following ligand activation is a major process in terminating RTK signaling, it was reasoned that the rapid decay in signaling in the SHP2-silenced cells might be related to effect on this process. To test this possibility, the same total cell lysates were analyzed for EGFR. The results showed that the level of EGFR in the SHP2-silenced cells was very low in the first place and rapidly degraded upon EGF stimulation (Fig.3G and H). To substantiate these findings, total cell lysates from the parental, the control, and the two SHP2 shRNA cells were analyzed for basal levels of the three RTKs. The results showed a 6-8 fold reduction in EGFR, FGFR, and c-MET levels the 
SHP2-silenced cells (Fig.3I). These findings confirmed that overexpression of the three RTKs that are commonly implicated in BTBC tumorigenesis is SHP2 dependent.

\section{C.4 SHP2 regulates the expression of $\beta$-catenin and its transcriptional targets in BTBC cells}

Based on previous reports that showed differential regulation of the $\mathrm{Wnt} / \beta$-catenin signaling pathway in BTBC $[62,63]$ and the reported positive role of SHP2 in this signaling pathway $[19,64]$, it was reasoned that SHP2 may regulated Wnt/ $\beta$-catenin signaling. This possibility is further supported by the drastic effect of SHP2 inhibition on cell proliferation and transformation which suggest the involvement of multiple signaling pathways. For this, the effect of SHP2 inhibition on the Wnt $/ \beta$ catenin pathway was studied. Because $\beta$-catenin stability is at the core of its signaling mechanism [65], the impact of SHP2 inhibition on total $\beta$-catenin protein level was studied first. The results showed a drastic reduction in $\beta$-catenin protein level in the SHP2-silenced cells (Fig.4A). Band density measurements further showed the presence of 8-10 fold $\beta$-catenin reduction in the SHP2-silenced cells (Fig.4B). As an indirect measure, we also determined the expression of two $\beta$-catenin target genes, cyclin D1 and c-Myc [66], under the same conditions. In agreement with the $\beta$-catenin level, cyclin D1 and c-Myc were significantly reduced in the SHP2-silenced cells (Fig.4A). These results show that SHP2 is required for $\beta$-catenin stability and expression of target genes in BTBC cells, which in turn suggest that one of the mechanisms by which SHP2 promotes BTBC is by promoting Wnt/ $\beta$-catenin signaling.

The low level of total $\beta$-catenin and its transcriptional targets in the SHP2-silenced cells was an indication for a low cytoplasmic and nuclear $\beta$-catenin pool. To verify this point, cytoplasmic and nuclear protein extracts were analyzed for $\beta$-catenin by immunoblotting experiments. While the controls had higher cytoplasmic and nuclear $\beta$-catenin, the SHP2-silenced cells had very low cytoplasmic and undetectable nuclear $\beta$-catenin (Fig.4C). Reprobing for poly-ADP ribose polymerase 
(PARP) and $\beta$-actin as nuclear and cytoplasmic markers, respectively, confirmed the integrity of the fractionation. To clarify this point further, $\beta$-catenin immunofluorescence (IF) studies were conducted. Consistent with the immunoblotting data, intense cytoplasmic and nuclear $\beta$-catenin staining was observed in the controls. On the other hand, the $\beta$-catenin signal in the SHP2-silenced cells was relatively low and mainly present at the plasma membrane (Fig.4D and E). These results confirm that SHP2 is required for cytoplasmic stability and nuclear localization of $\beta$-catenin in BTBC cells.

To determine whether the effect of SHP2 is at protein or mRNA level, time course proteasome inhibition with Mg-132 that included shorter and longer time points were conducted. As shown in Fig. $4 \mathrm{~F}$ and $\mathrm{G}, \beta$-catenin was restored within 3 hours in the SHP2-silenced cells. These findings are consistent with SHP2 promoting $\beta$-catenin stability by countering proteasomal degradation. Because regulation at a transcriptional level could not be ruled out, the effect of SHP2 silencing on $\beta$-catenin mRNA levels was determined by quantitative real-time PCR (qRT-PCR). The results showed no significant difference between the control and SHP2-silenced cells (Fig.4H), confirming that the effect of SHP2 is at a protein level.

\section{C.5 $\beta$-Catenin is essential for the growth and transformation of BTBC cells}

After demonstrating that SHP2 mediates $\beta$-catenin stability, it was logical to show whether or not $\beta$-catenin has any biological significance in BTBC cells. To address this point, the expression of $\beta$ catenin was silenced in the MDA-MB231 and MDA-MB468 cells using two independent shRNA constructs, $\beta$ sh 1 and $\beta$ sh2 (Fig.5A). In the same preparations, the levels of cyclin D1 and c-Myc, the $\beta$ catenin transcriptional target genes, were determined. The results showed a substantial decrease in both proteins (Fig.5A).

To test the biological significance of $\beta$-catenin in BTBC cells, the effect of silencing on cell

proliferation was determined by direct counting. The results showed an approximately $50 \%$ drop in cell proliferation rate (Fig.5B), suggesting that $\beta$-catenin is important for the growth of BTBC cells. 
Next, the effect of $\beta$-catenin silencing on cell transformation was determined by anchorageindependent growth in soft agar. Silencing $\beta$-catenin suppressed colony formation in terms of size and number (Fig.5C). Counting colony number showed formation of 22-25 colonies by the parental and the control cells, but only 7 - 9 colonies by the $\beta$-catenin-silenced cells per field under the $4 \times$ objective (Fig.5D). Hence, silencing $\beta$-catenin in BTBC cells suppresses proliferation and transformation.

\section{C.6 $\beta$-Catenin is directly involved in the transcription of EGFR}

Because EGFR was previously suggested to be a direct target of $\beta$-catenin transcriptional activity [67] and because SHP2 is essential for $\beta$-catenin stability, it was reasoned that the positive role of SHP2 on EGFR mRNA expression in BTBC cells might be through its effect on $\beta$-catenin. To verify this point, the effect of $\beta$-catenin silencing on EGFR protein levels was determined by IB. The results showed a profound reduction (Fig.5E), reminiscing the levels found in the SHP2-silenced cells. To see if SHP2 might also be a target of $\beta$-catenin, its protein level was also determined. Similar to RGFR, the protein level of SHP2 also was downregulated drastically (Fig.5E). To confirm that the effect of $\beta$ catenin silencing on EGFR and SHP2 was at a transcriptional level, the respective mRNAs were analyzed by qRT-PCR. The results showed an approximately 8-10 fold reduction in EGFR and SHP2 mRNA levels in the $\beta$-catenin-silenced cells (Fig.5F). These findings suggest that $\beta$-catenin is essential for EGFR and SHP2 transcription.

\section{Discussion}

Overexpression and Gene amplification of RTKs are a major mechanism for tumor growth and development in many forms of cancers[21, 33, 68]. EGFR and HER2 are overexpressed and gene amplified respectfully in some forms of $\mathrm{BC}$ and shown to be a driving factor leading to tumorigenesis[69-71]. SHP2 has been shown to be a positive mediator of both EGFR and HER2 in 
HER2 positive breast cancer and to promote down signaling between both RTKs. Many studies have been conducted to understand what causes such heterogeneity in BTBC that leads to dysregulation of multiple RTKs, a mutation in Ras, and dysregulated Wnt/beta-catenin signaling[72-74]. We are the first to show that silencing SHP2 in BTBC lead to a loss a tumor phenotype and SHP2 promotes signaling and expression of multiply RTKs and stabilizing $\beta$-catenin protein

Two BTBC cells MDA-MB 231 and MDA-468 cell lines that are known to overexpresses EGFR[54, 56] were used in this study. Logical these cells would be the best to see the effect of SHP2 silencing in BTBCs were SHP2 has been reported to be a positive mediator of EGFR signaling in HER2 positive breast cancer. Silencing of SHP2 with two previously reported shRNA in both cell lines led to losing of a mesenchymal phenotype and reduced a normal epithelial phenotype. There was also a loss of basal signaling in these SHP2 silenced BTBC cells to MAP kinase and PI3K/AKT pathways for survival and growth. Anchor independent growth of silenced SHP2 BTBC compared to control cell lines had a reduction in growth and overall colony size and number. Our data indicates that SHP2 needed to BTBC transformation phenotype which could be mediated by signaling to kinase and PI3K/AKT pathways.

The effect of SHP2 silencing in BTBC on cell proliferation and transformation was very dramatic compared to parental and control cell lines in both MDA-MB231 and MDA-MB468. This data aligns with the loss of basal signaling from AKT and ERK 1/2, pathways that regulate growth and survival in BTBCs. CSC phenotype was also lost with the silencing of SHP2 in both MDAMB231 and MDA-MB 468 as shown form the mammosphere assay, where during the second passage the mammospheres formed were lost only in SHP2 silenced MDA-MB231 and MDA-MB468. This was confirmed by cell sorting for the ALDH1 which is a marker for stem cells. Indeed the population of ALDH1 high cells in the mammospheres was dramatically reduced in SHP2 silenced cells 
compared to control cell lines, showing that SHP2 is regulating BTBC phenotype that has CSC properties that allow for growth in a 3D matrix.

With multiple RTK being dysregulated in BTBCs and with the observation that basal signaling was lower for Akt and ERK 1/2 SHP2 could have a role is signaling for other RTKs in BTBCs. This was indeed the case as shown with a loss of basal signaling form Akt and ERK 1/2 from FGF and HGF. Along with all three RTKs protein level being reduced in SHP2 silenced MDAMB231 and MDA-MB468 compared to control cell lines, SHP2 must play a protective role in the protein stability of these RTKs. As shown in figure $\mathbf{2 G}$ and $\mathbf{2 H}$ SHP2 was protective for EGFR degradation by EGF stimulation as seen with control cells have little loss of EGFR protein compared to SHP2 silenced cells when have a massive reduction in EGFR protein levels at 10 minutes of EGF stimulation in both MDA-MB231 and MDA-MB468. This data shows that SHP2 is essential for activation of Akt and ERK 1/2 form multiple RTK and that SHP2 has a role in protein stability for each of these dysregulated RTKs in BTBCs.

Wnt/Beta-catenin signaling has been shown to be dysregulated in BTBC, with overexpression of Wnt ligands[62, 75, 76]. A few studies have looked the functional role of $\beta$-catenin in BTBC with silencing $\beta$-catenin. $\beta$-catenin protein levels were also lower in SHP2 silenced cell lines. We wanted to see if $\beta$-catenin transcriptional targets were lower in SHP2 silenced MDA-MB231 and MDA-MB468 cells. The amount of protein for cyclin D1 and Myc were lower as expected, suggesting that ether the loss of $\beta$-catenin protein levels cause the loss of these transcriptional targets or that $\beta$ catenin was unable to translocate to the nucleus. With nuclear and cytoplasmic fraction studies, we showed that $\beta$-catenin was translocating in the nucleus only in control BTBCs and was only cytoplasmic in SHP2 silenced cells. Ifs for $\beta$-catenin in SHP2 silenced cells and control MDA-MB231 and MDA-MB468 show that $\beta$-catenin was manly at the plasma membrane in SHP2 silenced cells and control cells had both nuclear and cytoplasmic $\beta$-catenin. This data suggesting that SHP2 might be 
promoting the translocation of $\beta$-catenin, where SHP2 is overexpressed in BTBC. With MG132 treatment of MDA-MB231 and MDA-MB468 SHP2 silenced cells and control cells, protein level of $\beta$-catenin were able to come back to the level of control protein level after 6 hours of treatment along with no statistically difference in the amount of $\beta$-catenin mRNA in SHP2 silenced and control BTBCs. This would suggest that SHP2 also promotes the half of $\beta$-catenin protein levels, and this could be the reason for the loss of translocation to the nucleus in SHP2 silenced BTBCs .

The effect of $\beta$-catenin silencing in BTBCs showed similar results with the protein levels of $\beta$ catenin transcriptional target genes as in SHP2 silenced BTBCs, with both cyclin D1 and Myc. However with the rate of cellular proliferation and tumorigenesis in $\beta$-catenin silenced cells was not a dramatic as with SHP2 silencing as shown with growth rates and anchorage-independent growth. With protein levels of EGFR also being lowered in $\beta$-catenin silenced in BTBCs and SHP2 silenced BTBC could $\beta$-catenin be transcribing EGFR in BTBCs. As shown with RT-PCR , $\beta$-catenin silenced BTBCs, had level of EGFR mRNA corresponded with EGFR protein levels in $\beta$-catenin silenced BTBCs compare control cell lines. The importance of SHP2 for transformation in BTBCs was shown with EGFR mRNA expression was reduced in both SHP2 silenced and $\beta$-catenin silenced BTBCs and $\beta$-catenin mRNA expression was not affected by SHP2 silencing, suggesting that SHP2 is promoting transcription of EGFR by $\beta$-catenin protein stability.

More work is needed to understand what mechanism by which SHP2 plays in stabilizing $\beta$-catenin protein levels in BTBCs. Functional assays along with Chromatin immunoprecipitation could be done to show that $\beta$-catenin is a transcription factor EGFR in BTBCs. There is also the need to test if other RTKs such as FGFR and c-Met are under the same regulation as EGFR in BTBCs. In vivo studies are also needed to show that is novel feed-forward loop between EGFR/RTKs and Wnt/ $\beta$ catenin is functional and plays a major role in transformation in BTBCs. The data presented here shows a need to develop SHP2 inhibitors to the treatment of BTBCs. SHP2 seems to be a master 
regulator of signaling in BTBCs that we have shown to promotes that protein stability and expression of targets that are used today in clinics to treat cancer.

\section{E Material and Methods}

\section{E.1 Cells, cell culture and reagents}

The MDA-MB231 and the MDA-MB468 breast cancer cell lines and the MCF-10A normal breast epithelial cell line were purchased from American Type Culture Collection ( ATCC). All cells were

cultured Dulbecco's modified Eagle's medium supplemented with $10 \%$ fetal bovine serum at $37^{0} \mathrm{C}$ and 5\% carbon dioxide. Antibodies that were used in this study anti-EGFR (610017), anti-SHP2 (610822) and PARP (611038) from BD Biosciences, anti- $\beta$-catenin ( Sc-7199 and SC-37684), anti-cyclin D1 (SC-246), anti-pan-ERK2 (SC-81457), HSP 90 (SC-13119) formed Santa Cruz Biotechnology. The anti- $\beta$-actin (A5441) from Sigma-Aldrich, and anti-phospho-ERK 1/2 (9101S), anti-phospho-AKT (9271S) from Cell Signaling. Secondary antibodies conjugated to horseradish peroxidase anti-mouse, anti-rabbit and, anti-rat were from Jackson Immuno-Research Laboratories.

\section{E.2 Silencing SHP2, and $\beta$-catenin}

Silencing of SHP2 in MDA-MB231 and MDA-MB468 was described by our lab previously with two independent shRNA to show no off-target effects. The silencing $\beta$-catenin in MDA-MB231 and MDA-MB468, shRNA constructs (SHCLNG-NM_001904CTRCN0000314991 and TRCN0000314921) from Sigma were used. 293T cells were transfected with the shRNA constructs and supporting plasmids with FuGene ( Roche) transfection reagent, supernatants containing viral particles were collected 48 hours after transfection, and viral particles were used to infect target cells. 
$3 \mu \mathrm{g} / \mathrm{mL}$ of polybrene was added to increases the transfection efficiency. $1 \mu \mathrm{g} / \mathrm{mL}$ of puromycin was added after 48 hours for the selection of transfected cells.

\section{E.3 Cell lysates, Immunoblotting, and cytoplasmic-nuclear fraction analyzes}

Total cell lysates were prepared in cell lysis buffer containing 20mM Tris- $\mathrm{HCl}, \mathrm{pH}$ 7.2, $150 \mathrm{mM} \mathrm{NaCl}$, $50 \mathrm{mM} \mathrm{NaF}, 1 \mathrm{mM}$ EDTA, $10 \%$ triton-X-100, 1mM sodium orthovanadate and protease inhibitor cocktail. Total cell lysates were centrifuged at $12,000 \mathrm{rpm}$ for 10 minutes to clean lysates. Cytoplasmic and nuclear fraction were prepared as described previously with medication to cytoplasmic isolation buffer; we used cell lysis buffer in a 1:10 dilution from working concentration. Polyacrylamide gel electrophoresis was used to separate proteins and transfer to a nitrocellulose membrane and blocked with 3\% bovine serum albumin. Membranes were incubated with primary antibodies overnight at $4^{0} \mathrm{C}$; the fallowing day membranes were washed 3 times for 10 minutes with Tris-buffered saline with $0.1 \%$ Tween-20 (TBST). Secondary antibodies were incubated for 1 hour at room temperature and washed 3 times for 10 minutes with TBST. For detection of Immunoblotting, the chemiluminescence kit, Western Lighting kit was used

\section{E.4 Cell proliferation rate}

Cellular proliferation was determined by counting cells from microscopic pictures chosen randomly. Cells were seeded in $100 \mathrm{~mm}$ culture dishes, with 10 random pictures were taken with a $4 x$ objective immediately after attachment, and every 24 hours up to 3 days using an Olympus IX71 microscope with attached CCD and Microsuite Basic Edition software. The growth rate was determined by 
driving the average number of cells at each time point to the initial time point (number of the cell after attachment).

\section{E.5 Proteasome inhibition and EGF, FGF and HGF stimulation}

Cells lines were allowed to grow near confluence and were serum starved overnight. The fallowing day cells were treated with MG-132 a proteasome inhibitor or stimulated with $20 \mathrm{ng} / \mathrm{mL}$ of EGF, FGF or HGF for 6 hours. Cells were then harvested after 6 hours for downstream application for analysis in Immunoblotting or chromatin immunoprecipitation.

\section{E.6 Anchorage-independent growth assay and Mammosphere formation assay}

Anchorage-independent growth was used to determine cell transformation in soft agar as described

previously. The basement layer was formed by covering a $6 \mathrm{~cm}$ cell culture plates with $0.5 \%$ agar in growth medium and solidify by incubation at room temperature for 15 minutes aseptically. Approximately $10^{5}$ cells were then suspended in $2 \mathrm{~mL}$ of a mixture of growth medium and warm agar at a concentration of $0.3 \%$ and immediately poured onto the basement agar layer aseptically. Once fed layer solidifies, the plates were transferred to an incubator and maintained at $37^{\circ} \mathrm{C}$ and $5 \%$ carbon dioxide for 15 days and monitored for colony formation. The cells were fed with a mixture of growth medium and $0.3 \%$ agar twice, and feeding after that was with DMEM supplemented with $10 \%$ fetal bovine serum. Colony formation was monitored by visualization using an Olympus IX71 microscope with attached CCD and Microsuite Basic Edition software. Primary mammospheres were generated form bulk culterd cells and seeding ultra-low attachment plates, with 20,000 cells/ml in mammospheres media and allowed to grown to form mammospheres and was monitored by 
visualization using an Olympus IX71 microscope with attached CCD and Microsuite Basic Edition software. For passage of cells, spheres were collected and centrifuged gently and incubated for 3-5 minutes in $0.125 \%$ trypisn and cell cluster disrupted by pipetting throught a $200 \mu$ pipet tip. Microscope examination was done to see single cell suspension. For secondary mammnosphere formation singles cell suspensions from primary mammospheres were plated at $1,000 \mathrm{cells} / \mathrm{cm}^{2}$ in mammospheres media on ultra-low attachment plates and was monitored by visualization using an Olympus IX71 microscope with attached CCD and Microsuite Basic Edition software .

\section{E.7 ALDH activity}

The Aldefluor assay was used to identify and isolate stem-like cells form secondary mammospheres from SHP2 silenced cells and control cell lines. The assay was performed according to the manufacture's instructions, and the ALDH-positive/hi population identified by comparing flow profiles form cells incubated with and without an ALDH inhibitor. Cell sorting was performed at the WVU Flow Cytometry core.

\section{E. 8 Immnofluorescence microsopy.}

Cells were grown on a microscopic slide cover slip, cultures were fixed with $4 \%$ paraformaldehyde for 20 min, washed 3 times with phosphate-buffered saline (PBS), permeabilized with $0.2 \%$ Triton-X100 in PBS for 30 min, and blocked with 3\% bovine serum albumin in PBS for $1 \mathrm{~h}$. The samples were then stained with primary antibodies at $4{ }^{\circ} \mathrm{C}$ overnight, washed 3 times with phosphate-buffered saline containing $0.2 \%$ Triton-X-100, and incubated with fluorescent-labeled secondary antibodies for $1 \mathrm{~h}$ at room temperature. After washing three times, the chambers were removed, and slides were covered with appropriate size coverslips and sealed. Finally, slides were inverted and scanned with laser scanning microscope (LSM 510, Zeiss), and pictures were collected. 


\section{E.9 RNA isolation, cDNA synthesis, and RT-qPCR}

To determine mRNA expression in cells lines, SHP2 silenced, $\beta$-catenin silenced and control cell lines had total RNA isolated using TRizol reagent for Life Technologies following the manufacturer instructions. The amount of RNA from each cell line was then quantified using Nano drop from BioRad, with $2 \mu \mathrm{G}$ of RNA from each cell line used for cDNA synthesis by using the iScript Reverse Transcription Supermix For RT-qPCR from BioRad following the manufacturer instructions. cDNA from each cell line was then employed in RT-qPCR, primers for EGFR and $\beta$-catenin Primer time primer were purchased from Integrated DNA Technologies. EGFR mRNA expression a determined by using the iQ SYBR Green Supermix from BioRad and $\beta$-catenin mRNA expression by TaqMan Gene Expression Master Mix from Applied Biosystems, both RT-qPCR reaction were run using the iCycler iQ from BioRad. Data analysis was done by following the iCycler iQ instructions. Relative transcript quantities were calculated using the 2- $\Delta \Delta \mathrm{Ct}$ method with GAPDH as the endogenous reference gene. 
Figure 1A and $B$

A) Silencing SHP2 expression

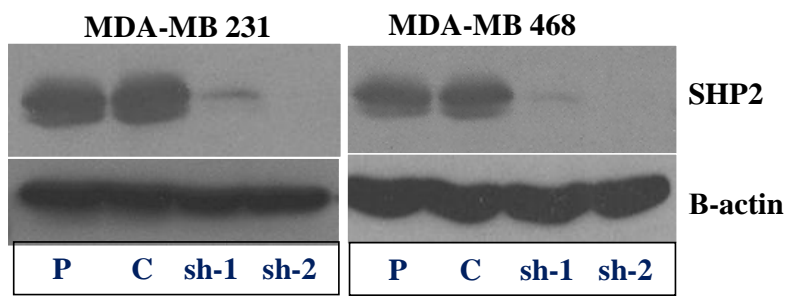

B) Silencing SHP2 inhibits basal signaling

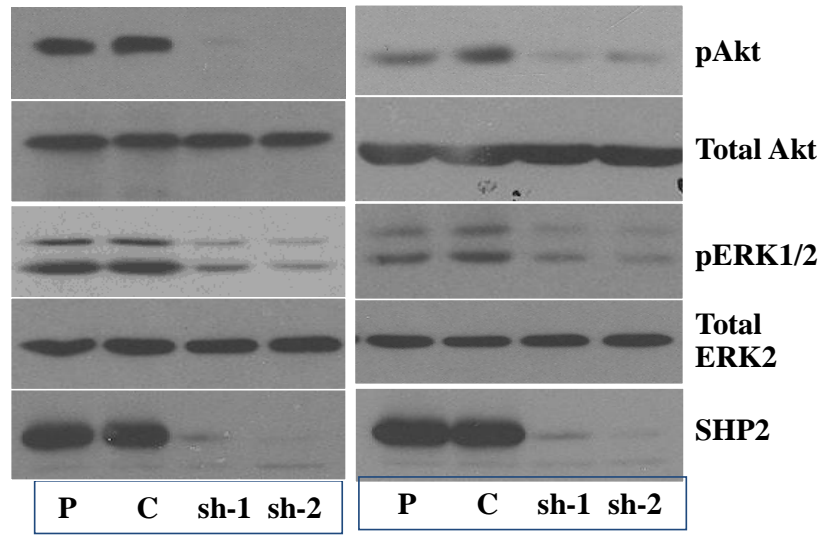

Figure 1C

C) Effect of SHP2 silencing on morphology, MDA-MB231

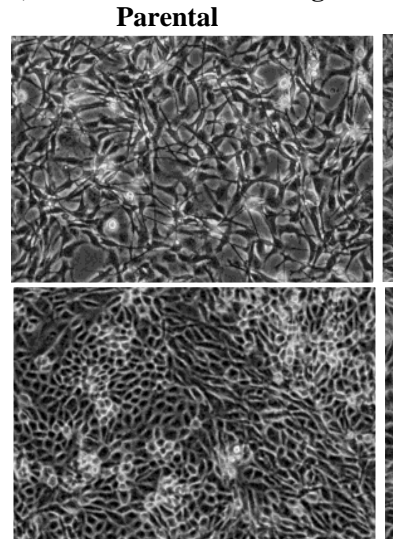

ShRNA-1 Control shRNA

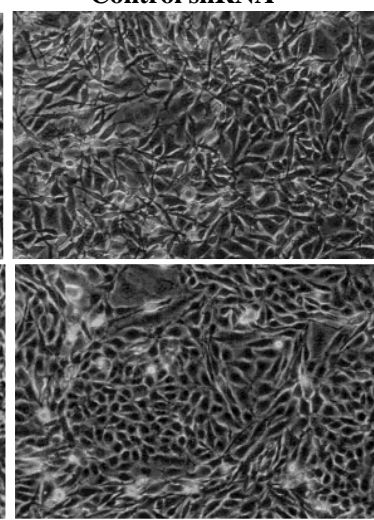

ShRNA-2

Figure 1D

D) Effect of SHP2 silencing on morphology, MDA-MB468

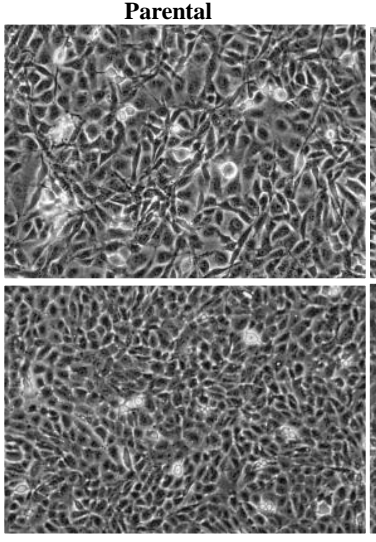

ShRNA-1 Control shRNA
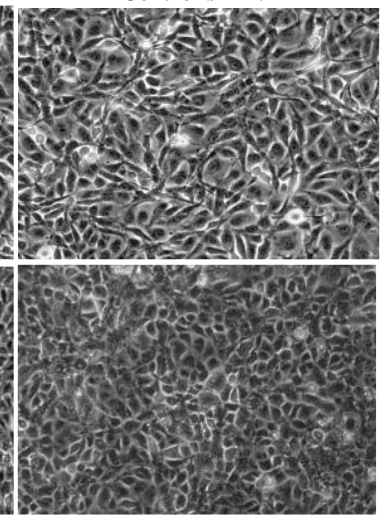

ShRNA-2

\section{D.1 Figure 1. Silencing of SHP2 in BTBC leads to reduction is transformation and basal signaling}

A. Western blot of two shRNA targeted for SHP2, empty viral control, and parental cells of MDAMB231 and MDA-MB468, anti- $\beta$-actin immunoblot used as loading control. B. Western blot of basal 
MAP kinase and PI3K/AKT pathway of silenced SHP2, empty viral control, and parental cells of MDA-MB231 and MDA-MB468. Ant-phospho-ERK1/2 and Anti-phospho-Akt blot used for activation of pathways, anti-pan-ERK2 and anti-pan-AKT blots used as loading controls C. SHP2 silenced MDA-MB231 and empty viral control MDA-MB231 and Parental MDA-MD231 cells grown to $90 \%$ confluency, observation of morphology under 4 x objective. D. SHP2 silenced MDA-MB468 and empty viral control MDA-MB468 and Parental MDA-MB468 cells grown to 90\% confluency, observation of morphology under 4 x objective.

Figure $2 A$ and $B$

\section{A) Effect on MDA-MB231 growth}

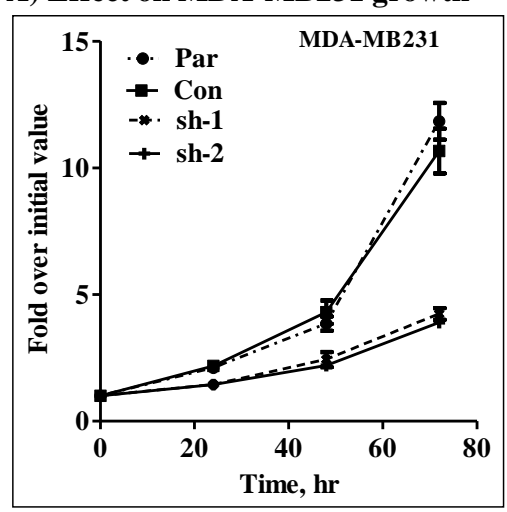

B) Effect on MDA-MB468 growth

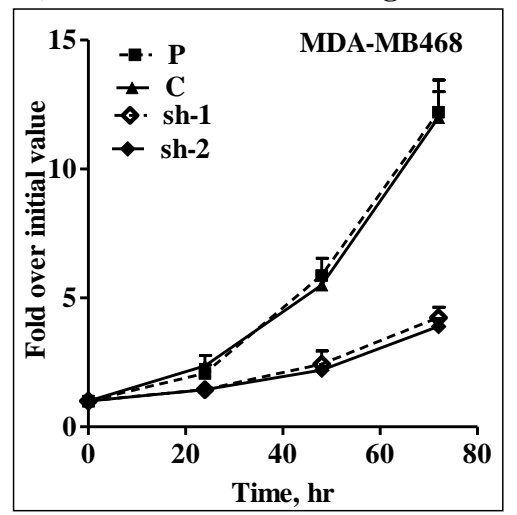

Figure 2C

C) Effect on colony formation

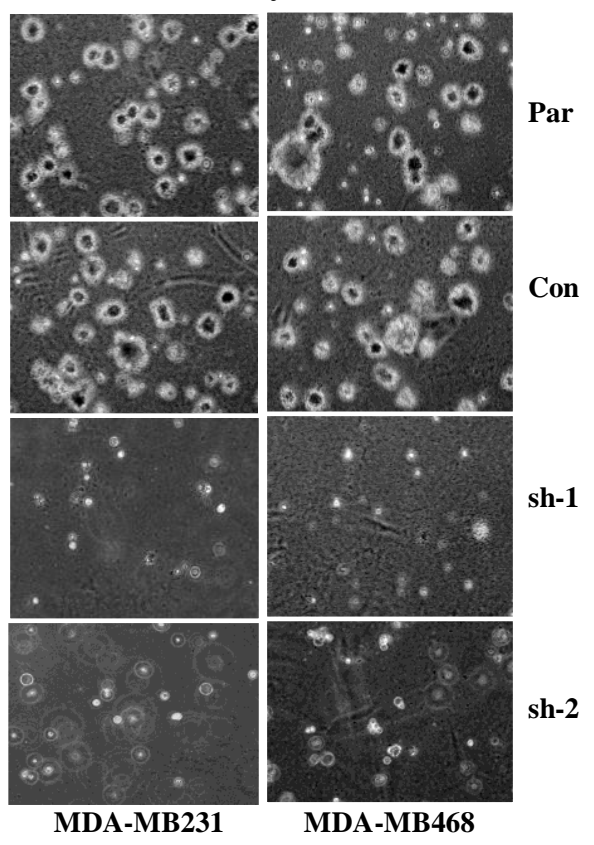


Figure 2D

D) Effect on colony number

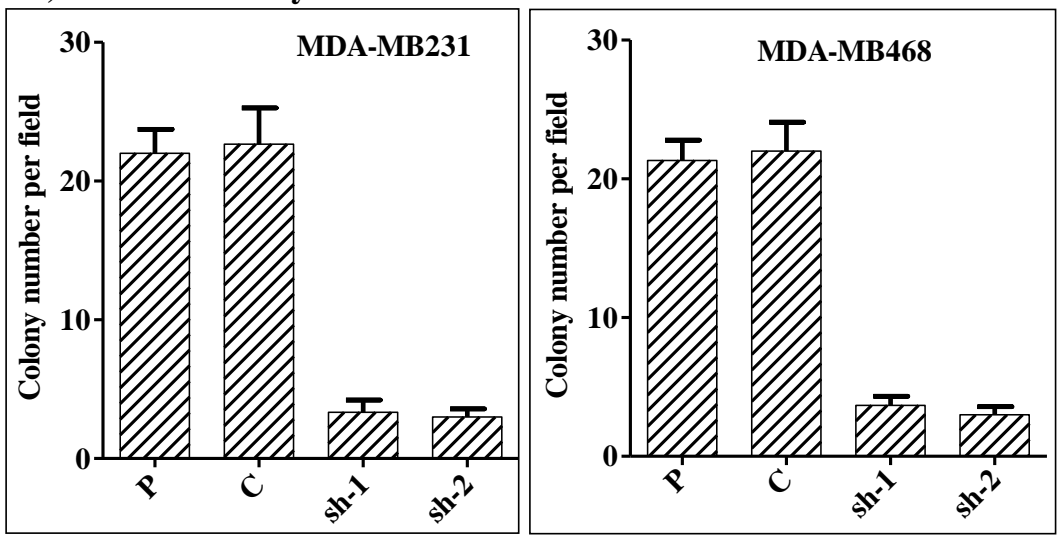

Figure 2E

E) Effect on CSC phenotypes

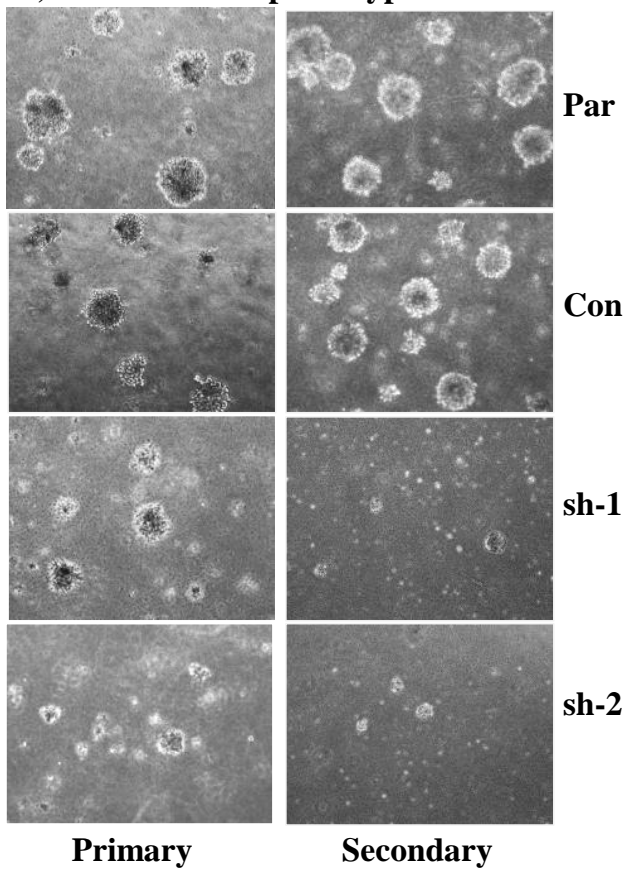

Figure 2F

F) ALDH1 activity, MDA-MB231
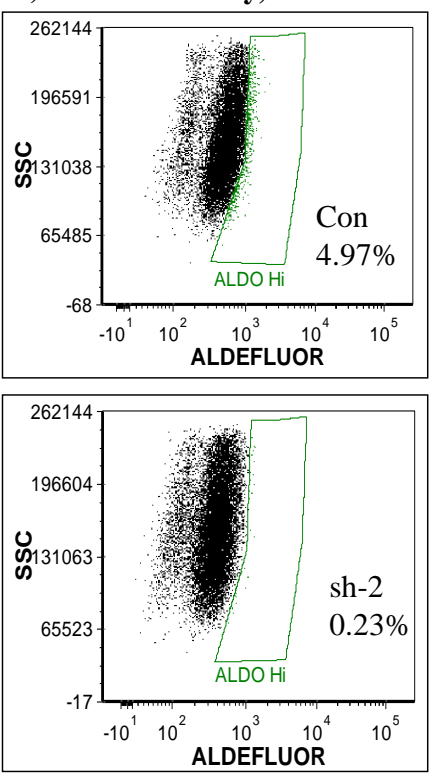
Figure 2G

G) Effect on CSC phenotypes, MDA-MB468

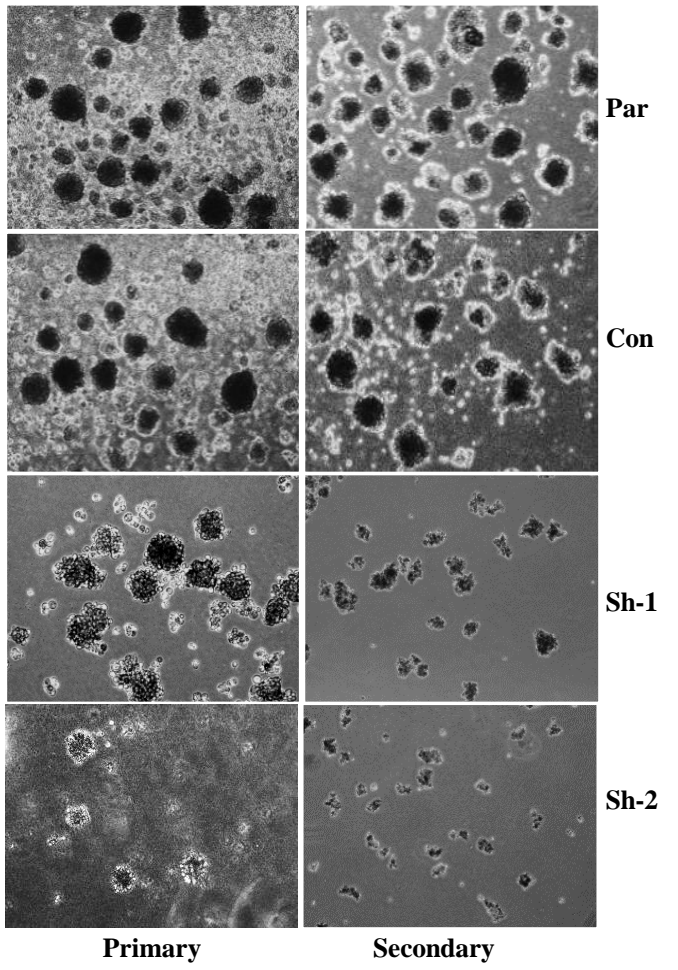

Figure 2H

H) ALDH1 activity, MDA-MB468
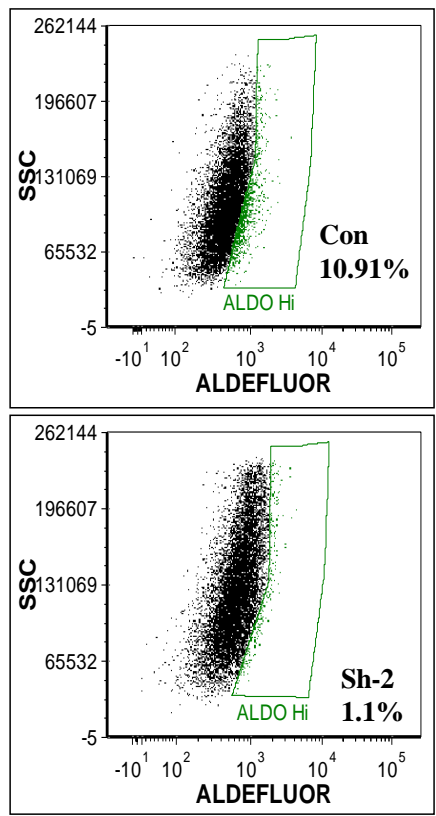


\section{D.2 Figuer2) Effect of SHP2 silencing on cell proliferation, transformation and CSC population}

in BTBCs A. Silenced SHP2 MDA-MB231 and empty viral control MDA-MB231 and parental MDA-MB231 were grown for 96 hours in DMEM and number of the cells were counted every 24 hours after the initial count to see the rate of cellular proliferation B. Silenced SHP2 MDA-MB468 and empty viral control MDA-MB468 and parental MDA-M B468 were grown for 96 hours in DMEM and number of the cells were counted every 24 hours after the initial count to see the rate of cellular proliferation C. Anchorage-independent growth assay of silenced SHP2, silenced EGFR and parental cell lines of MDA-MB231 and MDA-MB468. Images were taken under 10 x objective after 15 days; D. Bar graph shows quantification of colonies formed from each cell line MDA-MB231 and MDAMB468. E, G Mammosphere formation of MDA-MB231 and MDA-MD468 respectfully of SHP2 silenced, empty viral control and parental cells. Primary mammospheres in first column and secondary passage mammospheres second column. F, H Cells sorting of secondary passage mammospheres of MDA-MB231 and MDA-MB468 respectfully for ALDH1 high population of cells in control and SHP2 silenced mammospheres. 
Figure 3A and $B$

A) Effect of SHP2 on EGF signaling, MDA-MB231

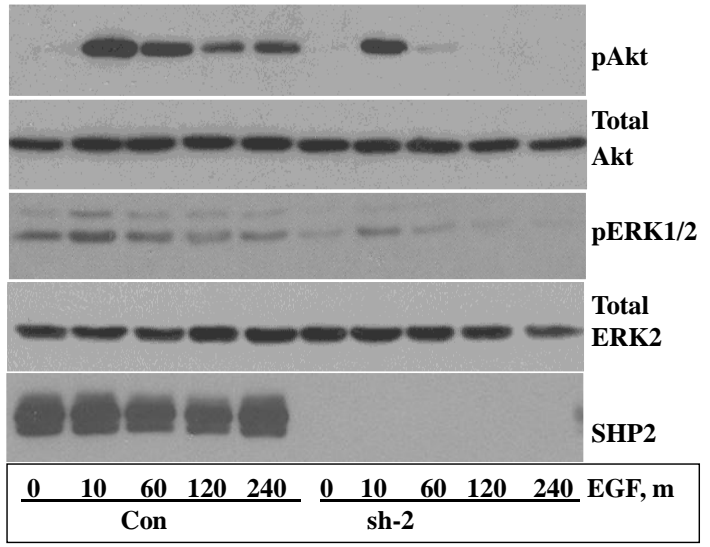

C) Effect of SHP2 on FGF signaling, MDA-MB231

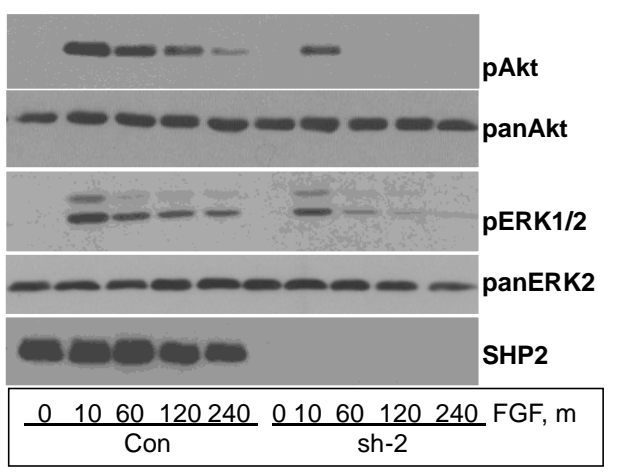

A) Effect of SHP2 on EGF signaling, MDA-MB468

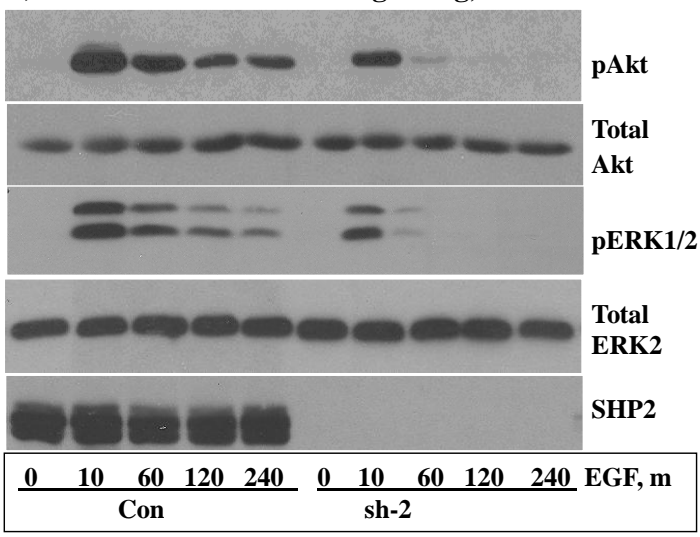

D) Effect of SHP2 on FGF signaling, MDA-MB468

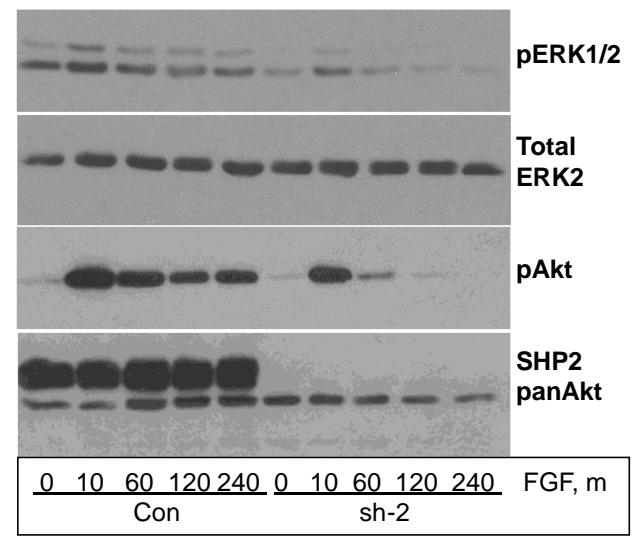


E) Effect of SHP2 on HGF signaling, MDA-MB231

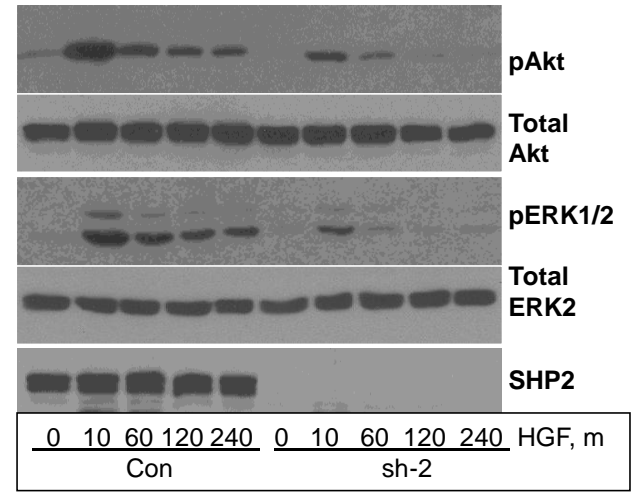

G) Effect of SHP2 on EGFR degradation, MDA-MB231

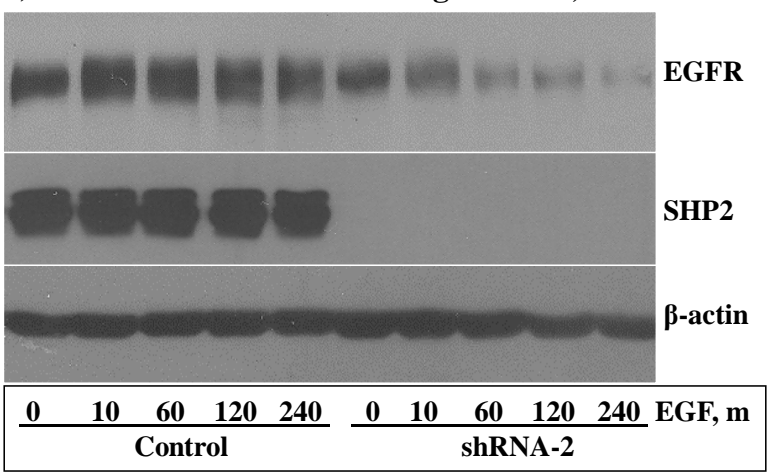

F) Effect of SHP2 on HGF signaling, MDA-MB468

H) Effect of SHP2 on EGFR degradation, MDA-MB468
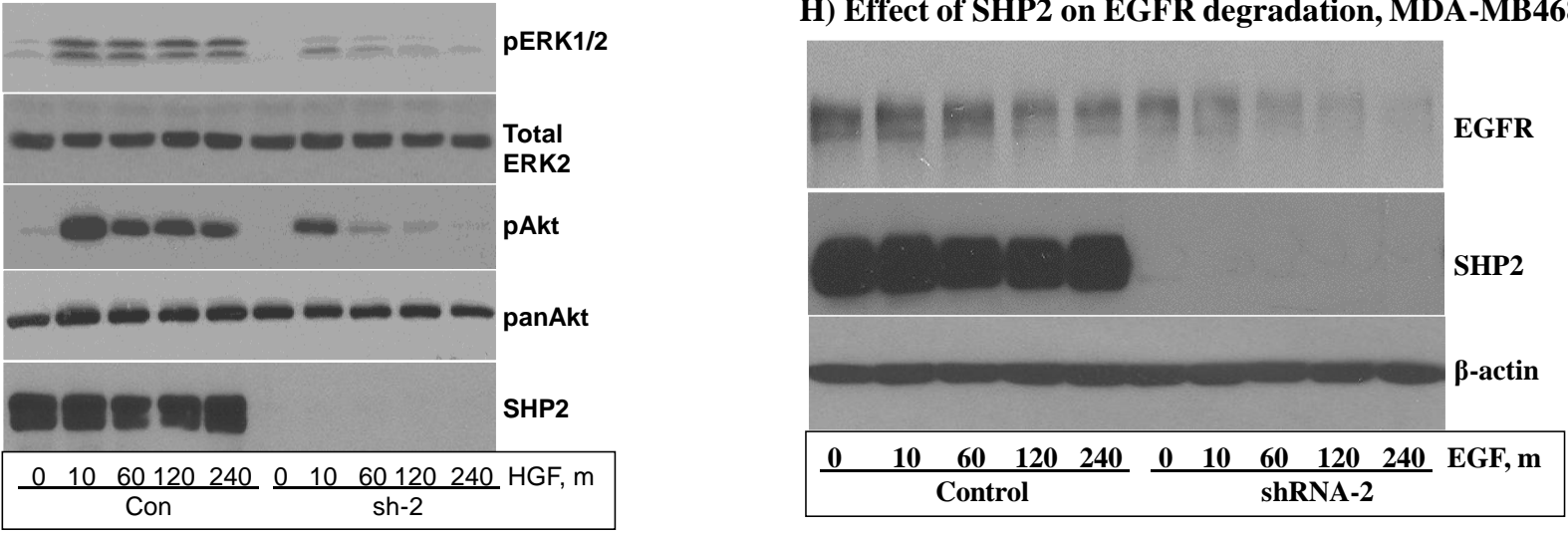

I) Effect of SHP2 on RTK expression

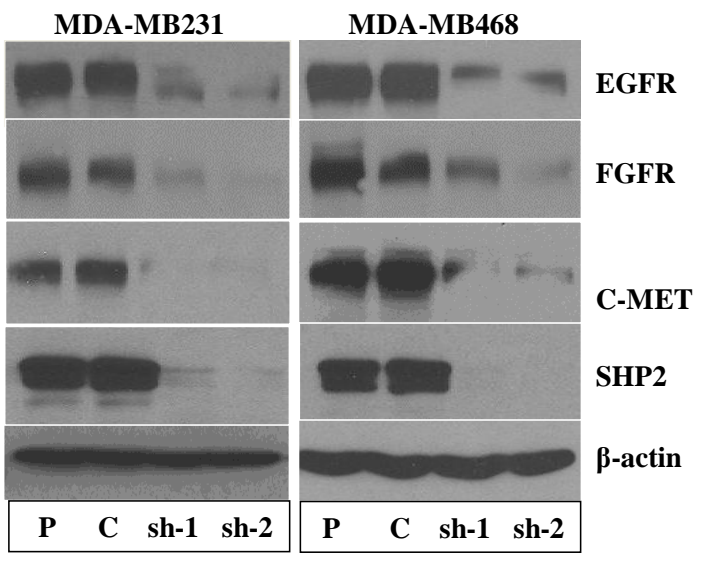

D.3 Figure 3. Silencing of SHP2 leads to a loss of siganling and expression of mutplitpal RTKs

in BTBCs A, B, MDA-MB231 and MDA-MB468 respectfully of SHP2 silenced sh-2, empty viral 
control were stimulated with $20 \mathrm{ng} / \mathrm{ml}$ of EGF for 4 hours.

C, D MDA-MB231 and MDA-MB468 respectfully of SHP2 silenced sh-2, empty viral control were stimulated with $20 \mathrm{ng} / \mathrm{ml}$ of FGF for 4 hours. E, F MDA-MB231 and MDA-MD468 respectfully of SHP2 silenced sh-2, empty viral control were stimulated with $20 \mathrm{ng} / \mathrm{ml}$ of HGF for 4 hours. All Western blots from A-F were analyzed for Ant-phospho-ERK1/2 and Anti-phospho-Akt blot used for activation of pathways, anti-pan-ERK2 and anti-pan-AKT blots used as loading controls during times-course stimulation from control and SHP2 silenced sh-2 cell lines. G,H MDA-MB231 and MDA-MD468 respectfully of SHP2 silenced sh-2, empty viral control were stimulated with $20 \mathrm{ng} / \mathrm{ml}$ of EGF for 4 hours. Western blots were analyzed for anti-EGFR during the time-course stimulation, anti- $\beta$-actin immunoblot used as loading control. Western Blot of MDA-MB231 and MDA-MD468 SHP2 silenced sh-1, sh-2, empty viral control and parental cell lines. bolts were analyzed for EGFR, FGR and C-MET with Anti-EGFR, anti-FGFR, anti-C-MET with, anti- $\beta$-actin immunoblot used as loading control.

\section{A) Effect of SHP2 on $\beta$-catenin}

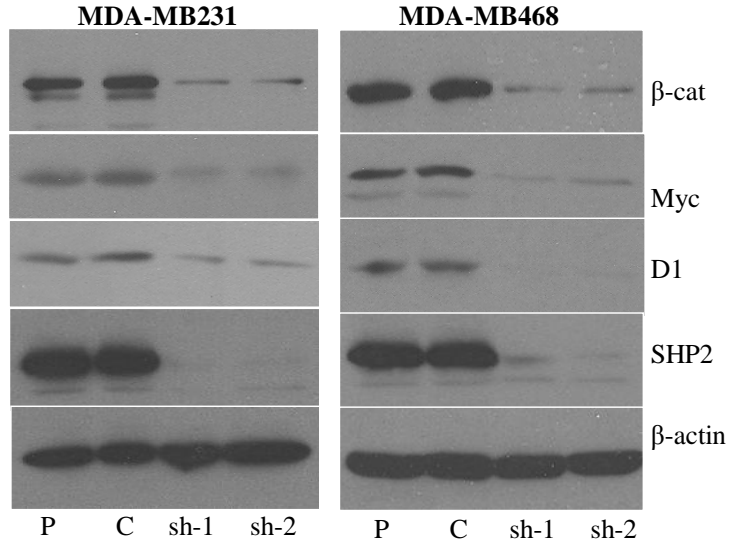

B) Effect of SHP2 on $\beta$-catenin, band density

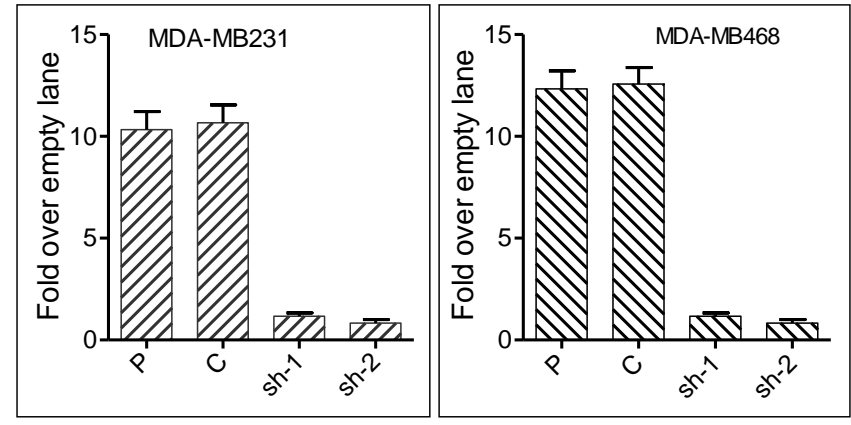

C) Subcellular levels of $\beta$-catenin MDA-MB231
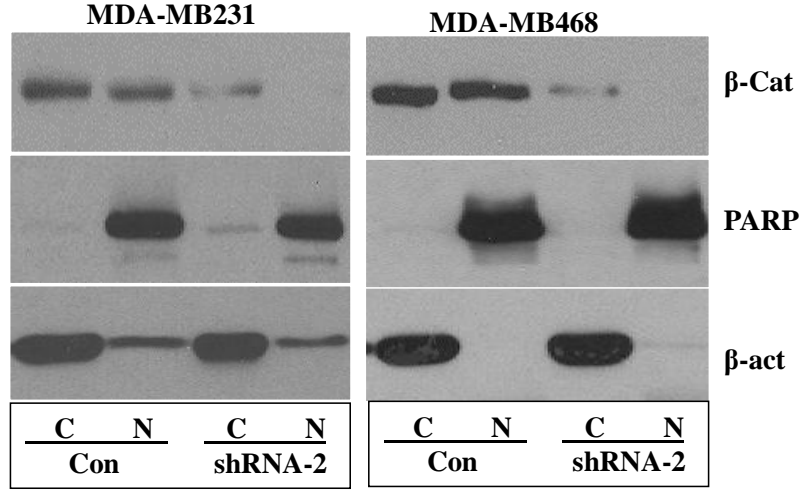
D) IF staining for $\beta$-catenin, MDA-MB231

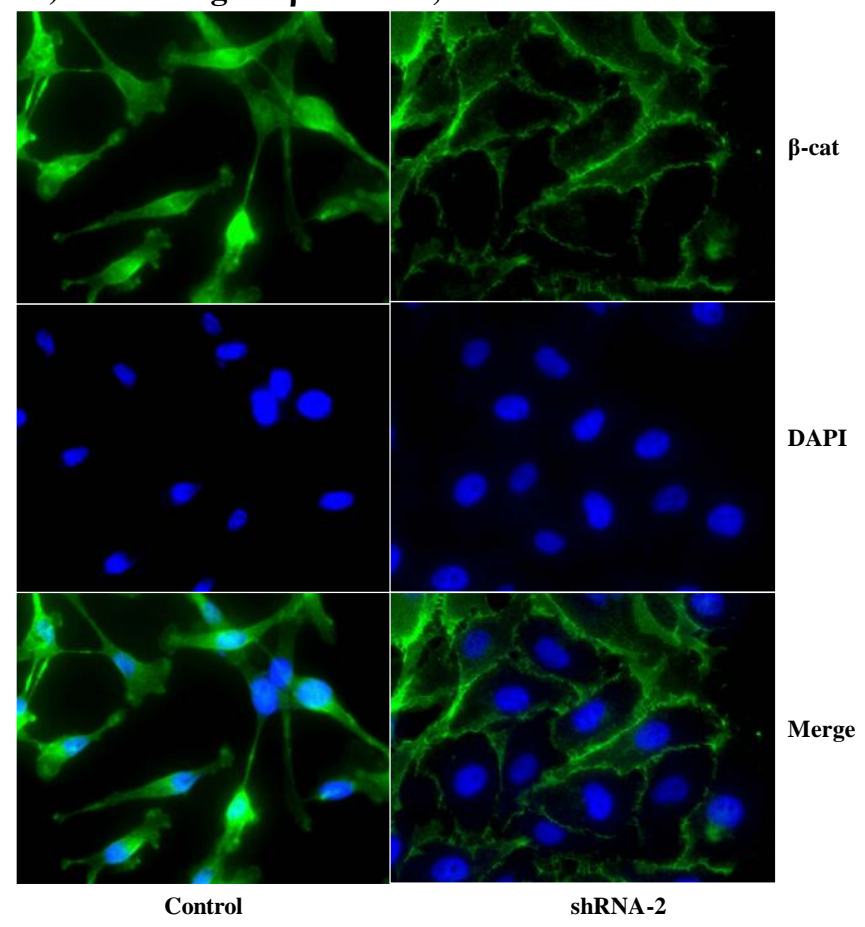

E) IF staining for $\beta$-catenin, MDA-MB468

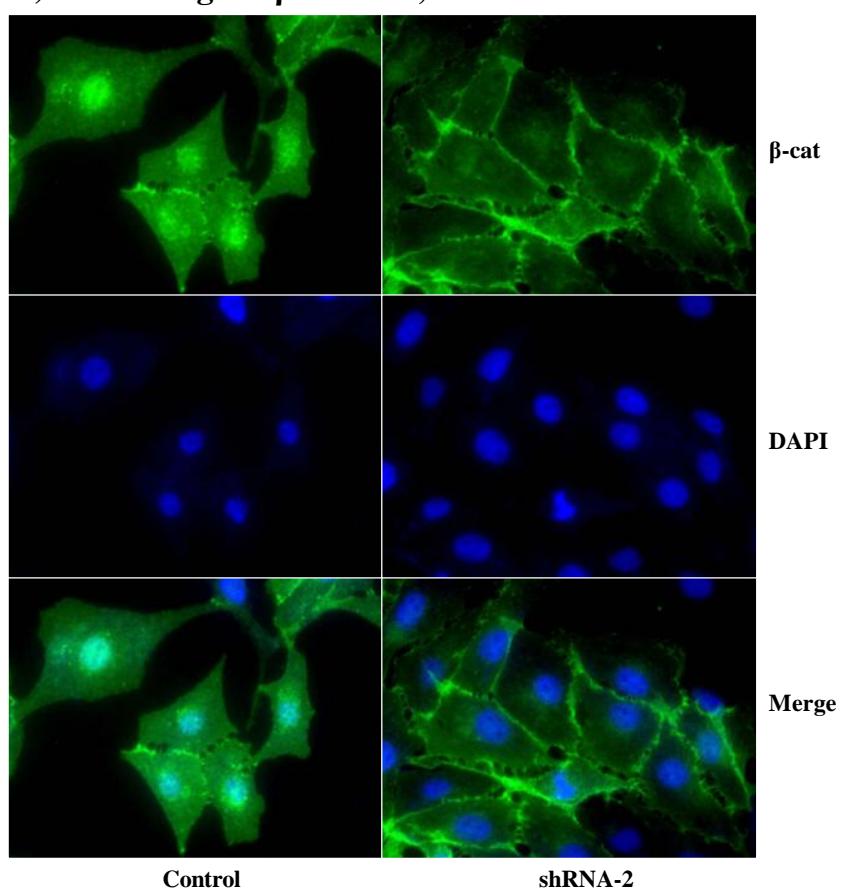

F) $M g 132$ restores $\beta$-catenin

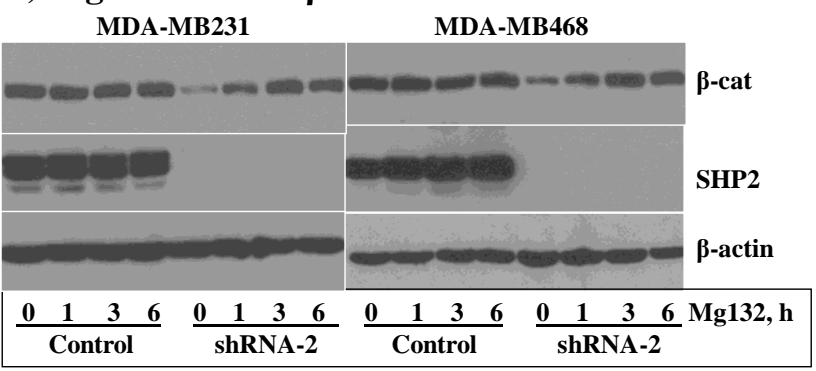

H) $\boldsymbol{\beta}$-catenin mRNA

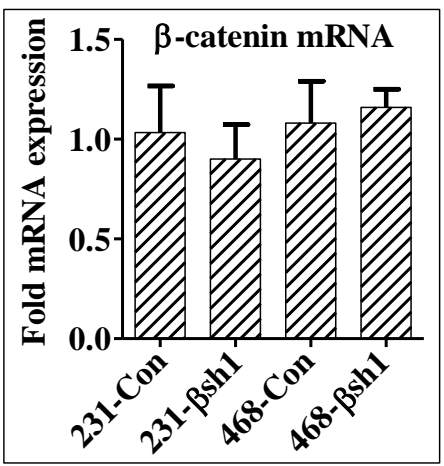

G) Mg132, $\beta$-catenin band density

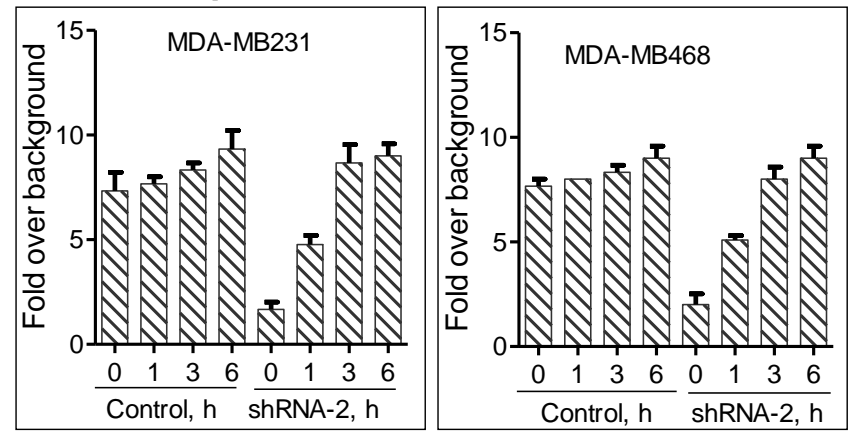




\section{D.4 Figure 4. SHP2 promotes mRNA expression of EGRF in BTBCs.}

A. Western blot for $\beta$-catenin target genes from SHP2 silenced MDA-MB231 and MDA-MB468, empty viral vector control, and parental cell line, Western blots were analyzed for anti-cyclin D1, antiMyc, anti-SHP2 and $\beta$-catenin, anti- $\beta$-actin immunoblot used as loading control B. Bar graph shows quantification of band density cell line MDA-MB231 and MDA-MB468. C Cytoplasmic and nuclear isolation from, MDA-MB231 and MDA-MB468 SHP2 silenced and control cell lines. Wester blot analyed for $\beta$-catenin in the nucleus or cytoplasm by anti- for $\beta$-catenin with anti-PARP and anti- $\beta$ actin as nuclear and cytoplasmic loading controls respectfully . D, E. $\beta$-catenin Immunoflurosecence of MDA-MB231 and MDA-MB468 respectfully of SHP2 silenced sh-2, empty viral control. Labeled anti- $\beta$-catenin was used to visualize the subcelluar location of $\beta$-catenin in SHP2 silenced cells and control . F. Proteasome inhibition treatment of SHP2 silenced sh-2 and control of MDA-MB231 and MDA-MB468. Both cells were serum starved overnight and the addition of MG-132 to inhibit the proteasome for 6 hours. Immunoblot for $\beta$-catenin to observe protein stability of $\beta$-catenin in SHP2 silenced MDA-MB231 and MDA-MB468 G. Bar graph show shows quantification band density form F for each cell line MDA-MB231 and MDA-MB468. H, Real-time qPCR for $\beta$-catenin mRNA expression in SHP2 silenced and parental MDA-MB231 and MDA-MB468.

A) Silencing $\beta$-catenin

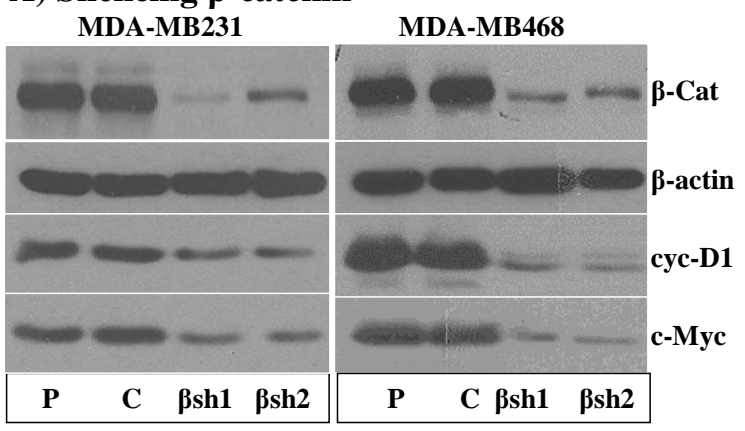

B) Effect of $\beta$-catenin silencing on cell growth

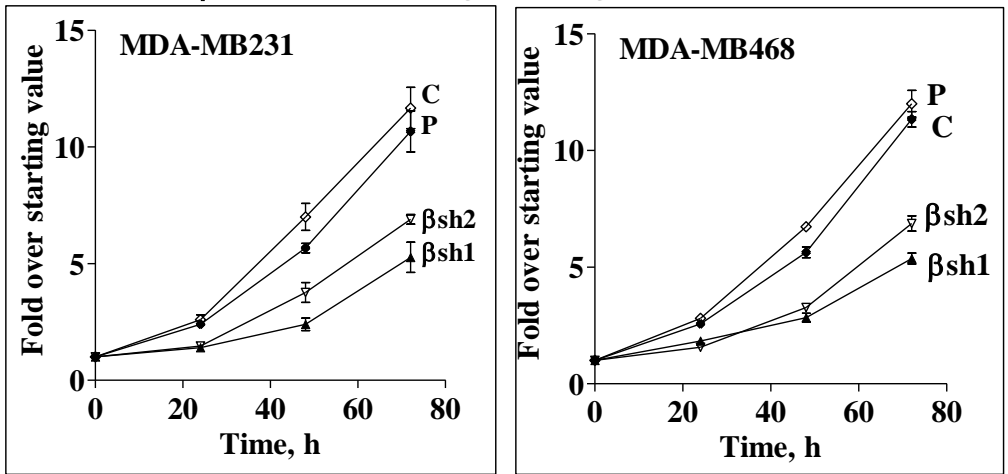


C) Effect of $\beta$-catenin silencing on colony formation

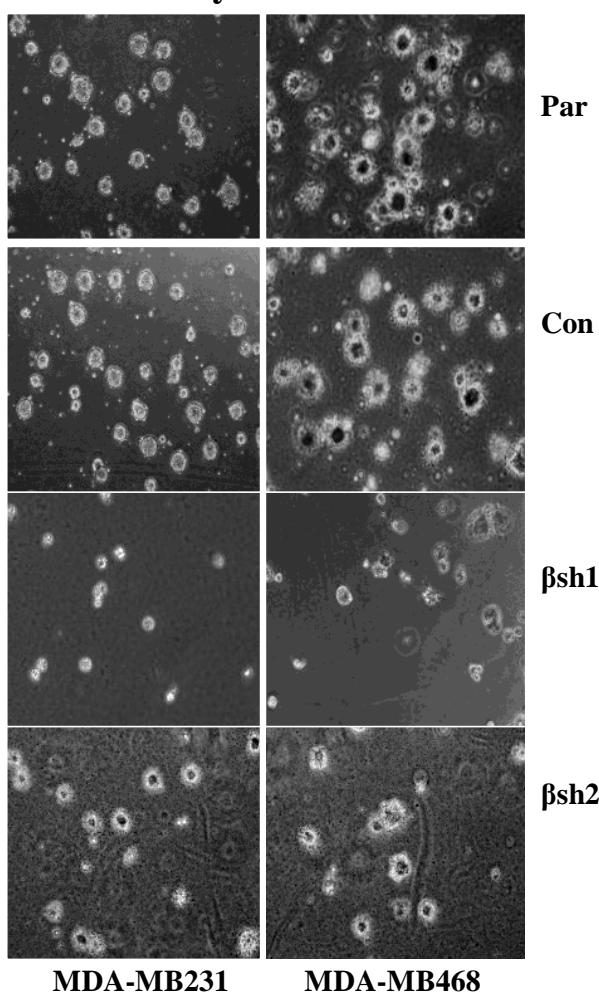

D) Effect of $\beta$-catenin on colony number

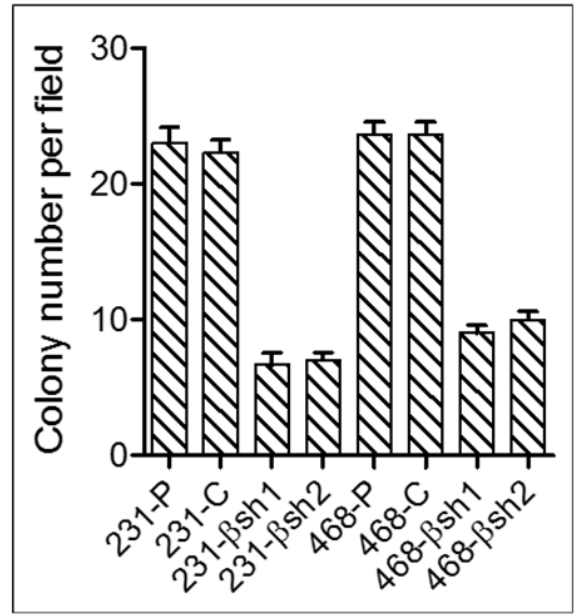




\section{E) Effect of $\beta$-catenin EGFR and SHP2 expression}

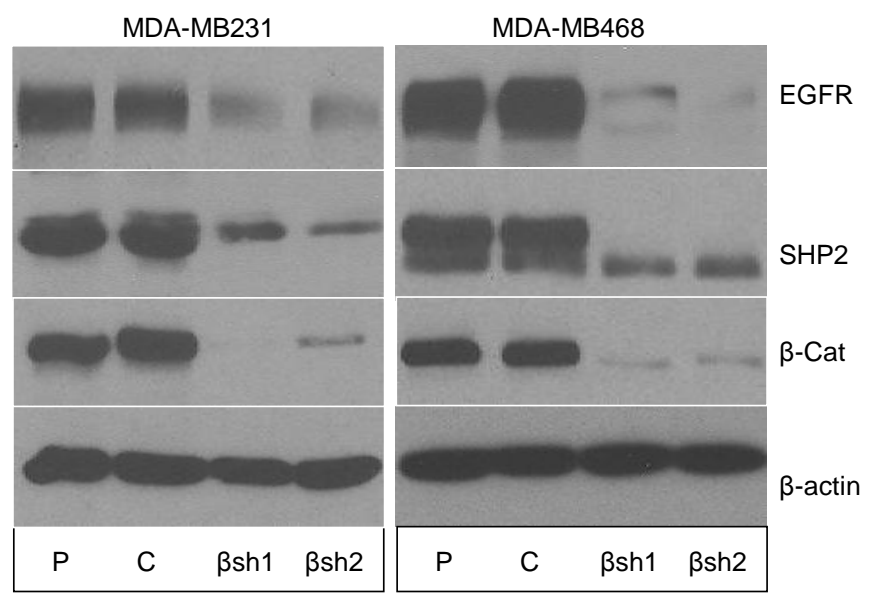

\section{F) EGFR and SHP2 mRNA}

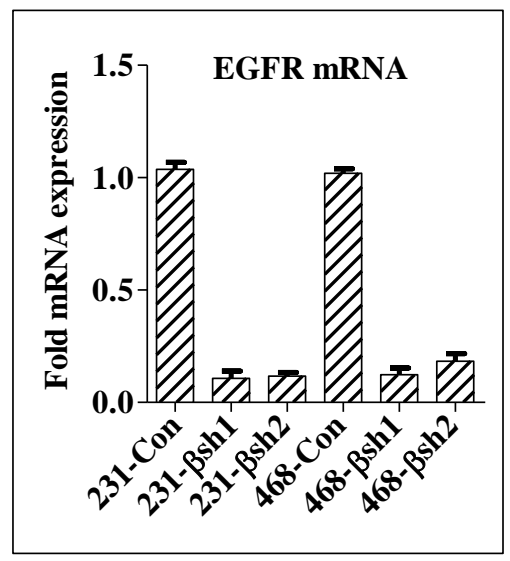

\section{D.5 Figure 5. EGFR is a transcriptional target of $\beta$-catenin in BTBCs}

A) Silencing of $\beta$-catenin is MDA-MB231 and MDA-MB468, two independent shRNA for $\beta$-catenin, empty viral vector control, and parental cell lines, immunoblot of $\beta$-catenin, cyclin D1 and Myc with anti- $\beta$-catenin, anti-cyclin D1 and anti-Myc with immunoblot of anti- $\beta$-actin as a loading control. B . Silenced $\beta$-catenin MDA-MB231 and MDA-MB 468 with empty viral control and parental cell lines were grown for 96 hours in DMEM and number of the cells were counted every 24 hours after the initial count to see the rate of cellular proliferation. C. Anchorage-independent growth assay form silenced $\beta$-catenin and silenced SHP2 MDA-MB231 and MDA-MB468. Images were taken under 10 x objective after 15 days D. Bar graph shows quantification of colonies formed from each cell line in 
E. Western Blot of $\beta$-catenin silenced MDA-MB231 and MDA-MB 468 with empty viral control and parental cell lines. Blots were analyzed for EGFR and SHP2 with anti-EGFR and anti-SHP2 with, anti- $\beta$-actin immunoblot used as loading control. F. Real-time qPCR for EGFR mRNA expression in $\beta$-catenin silenced and parental MDA-MB231 and MDA-MB468. 


\section{F. References}

1. Cakar B, Muslu U, Erdogan AP, Ozisik M, Ozisik H, Tunakan Dalgic C, Durusoy R, Karaca B, Sezgin C, Karabulut B et al: The Role of Body Mass Index in Triple Negative Breast Cancer. Oncology research and treatment 2015, 38(10):518-522.

2. Macacu A, Autier P, Boniol M, Boyle P: Active and passive smoking and risk of breast cancer: a meta-analysis. Breast Cancer Res Treat 2015, 154(2):213-224.

3. Kasajova P, Holubekova V, Mendelova A, Lasabova Z, Zubor P, Kudela E, Biskupska-Bodova K, Danko J: Active cigarette smoking and the risk of breast cancer at the level of $\mathrm{N}$ acetyltransferase 2 (NAT2) gene polymorphisms. Tumour biology : the journal of the International Society for Oncodevelopmental Biology and Medicine 2015.

4. Breast Cancer Review | Breast Cancer in the U.S. In.

5. Upadhyay R, Butt QU, Hamaoui A, Henderson C, McCalla S, Gilak H: Triple Negative Breast Cancer in Pregnancy and Postpartum: Two Case Reports in Hispanic Women. Case reports in obstetrics and gynecology 2015, 2015:856931.

6. Brewster AM, Chavez-MacGregor M, Brown P: Epidemiology, biology, and treatment of triplenegative breast cancer in women of African ancestry. The Lancet Oncology 2014, 15(13):e625e634.

7. What are the risk factors for breast cancer? In.

8. Key TJ, Verkasalo PK, Banks E: Epidemiology of breast cancer. The Lancet Oncology 2001, 2(3):133-140.

9. Rengarajan T, Rajendran P, Nandakumar N, Balasubramanian MP, Nishigaki I: The epidemiology of human breast cancer. International Journal of Medical and Health Sciences 2014, 3(1):62-71.

10. Bao PP, Cai H, Peng P, Gu K, Su Y, Shu XO, Zheng Y: Body mass index and weight change in relation to triple-negative breast cancer survival. Cancer causes \& control : CCC 2016, 27(2):229-236.

11. Kotsopoulos J, Huzarski T, Gronwald J, Moller P, Lynch HT, Neuhausen SL, Senter L, Demsky R, Foulkes WD, Eng $C$ et al: Hormone replacement therapy after menopause and risk of breast cancer in BRCA1 mutation carriers: a case-control study. Breast Cancer Res Treat 2016, 155(2):365-373.

12. Lupo M, Dains JE, Madsen LT: Hormone Replacement Therapy: An Increased Risk of Recurrence and Mortality for Breast Cancer Patients? Journal of the advanced practitioner in oncology 2015, 6(4):322-330.

13. Francies FZ, Wainstein T, De Leeneer K, Cairns A, Murdoch M, Nietz S, Cubasch H, Poppe B, Van Maerken T, Crombez B et al: BRCA1, BRCA2 and PALB2 mutations and CHEK2 c.1100delC in different South African ethnic groups diagnosed with premenopausal and/or triple negative breast cancer. BMC Cancer 2015, 15:912.

14. Brenton JD, Aparicio SA, Caldas C: Molecular profiling of breast cancer: portraits but not physiognomy. Breast cancer research : BCR 2001, 3(2):77-80.

15. Perou CM, Sorlie T, Eisen MB, van de Rijn M, Jeffrey SS, Rees CA, Pollack JR, Ross DT, Johnsen H, Akslen LA et al: Molecular portraits of human breast tumours. Nature 2000, 406(6797):747752.

16. Sorlie T: Molecular portraits of breast cancer: tumour subtypes as distinct disease entities. European journal of cancer 2004, 40(18):2667-2675.

17. Ahmed Z, George R, Lin CC, Suen KM, Levitt JA, Suhling K, Ladbury JE: Direct binding of Grb2 SH3 domain to FGFR2 regulates SHP2 function. Cellular signalling 2010, 22(1):23-33. 
18. Ahmed Z, Lin CC, Suen KM, Melo FA, Levitt JA, Suhling K, Ladbury JE: Grb2 controls phosphorylation of FGFR2 by inhibiting receptor kinase and Shp2 phosphatase activity. The Journal of cell biology 2013, 200(4):493-504.

19. Burks J, Agazie YM: Modulation of alpha-catenin Tyr phosphorylation by SHP2 positively effects cell transformation induced by the constitutively active FGFR3. Oncogene 2006, 25(54):7166-7179.

20. Hadari YR, Kouhara H, Lax I, Schlessinger J: Binding of Shp2 tyrosine phosphatase to FRS2 is essential for fibroblast growth factor-induced PC12 cell differentiation. Molecular and cellular biology 1998, 18(7):3966-3973.

21. Li J, Reed SA, Johnson SE: Hepatocyte growth factor (HGF) signals through SHP2 to regulate primary mouse myoblast proliferation. Experimental cell research 2009, 315(13):2284-2292.

22. Mali RS, Ma P, Zeng LF, Martin H, Ramdas B, He Y, Sims E, Nabinger S, Ghosh J, Sharma N et al: Role of SHP2 phosphatase in KIT-induced transformation: identification of SHP2 as a druggable target in diseases involving oncogenic KIT. Blood 2012, 120(13):2669-2678.

23. Miura K, Wakayama $Y$, Tanino $M$, Orba $Y$, Sawa H, Hatakeyama M, Tanaka S, Sabe H, Mochizuki N: Involvement of EphA2-mediated tyrosine phosphorylation of Shp2 in Shp2regulated activation of extracellular signal-regulated kinase. Oncogene 2013.

24. Cheang MC, Voduc D, Bajdik C, Leung S, McKinney S, Chia SK, Perou CM, Nielsen TO: Basal-like breast cancer defined by five biomarkers has superior prognostic value than triple-negative phenotype. Clinical cancer research : an official journal of the American Association for Cancer Research 2008, 14(5):1368-1376.

25. Ihemelandu CU, Naab TJ, Mezghebe HM, Makambi KH, Siram SM, Leffall LD, Jr., Dewitty RL, Jr., Frederick WA: Basal cell-like (triple-negative) breast cancer, a predictor of distant metastasis in African American women. American journal of surgery 2008, 195(2):153-158.

26. Rakha EA, Ellis IO: Triple-negative/basal-like breast cancer: review. Pathology 2009, 41(1):4047.

27. Rakha EA, El-Sayed ME, Green AR, Lee AH, Robertson JF, Ellis IO: Prognostic markers in triplenegative breast cancer. Cancer 2007, 109(1):25-32.

28. Rakha EA, El-Sayed ME, Reis-Filho J, Ellis IO: Patho-biological aspects of basal-like breast cancer. Breast cancer research and treatment 2009, 113(3):411-422.

29. Baselga J, Albanell J, Ruiz A, Lluch A, Gascon P, Guillem V, Gonzalez S, Sauleda S, Marimon I, Tabernero JM et al: Phase II and tumor pharmacodynamic study of gefitinib in patients with advanced breast cancer. Journal of clinical oncology : official journal of the American Society of Clinical Oncology 2005, 23(23):5323-5333.

30. Bayraktar S, Gluck S: Molecularly targeted therapies for metastatic triple-negative breast cancer. Breast cancer research and treatment 2013, 138(1):21-35.

31. Tartaglia M, Mehler EL, Goldberg R, Zampino G, Brunner HG, Kremer H, van der Burgt I, Crosby $A H$, lon A, Jeffery $S$ et al: Mutations in PTPN11, encoding the protein tyrosine phosphatase SHP-2, cause Noonan syndrome. Nature genetics 2001, 29(4):465-468.

32. Tartaglia $M$, Niemeyer CM, Fragale A, Song $X$, Buechner J, Jung $A$, Hählen $K$, Hasle $H$, Licht JD, Gelb BD: Somatic mutations in PTPN11 in juvenile myelomonocytic leukemia, myelodysplastic syndromes and acute myeloid leukemia. Nature genetics 2003, 34(2):148-150.

33. Tartaglia M, Kalidas K, Shaw A, Song X, Musat DL, van der Burgt I, Brunner HG, Bertola DR, Crosby A, lon A et al: PTPN11 mutations in Noonan syndrome: molecular spectrum, genotypephenotype correlation, and phenotypic heterogeneity. American journal of human genetics 2002, 70(6):1555-1563.

34. Tartaglia M, Martinelli S, lavarone I, Cazzaniga G, Spinelli M, Giarin E, Petrangeli V, Carta C, Masetti R, Aricò $M$ et al: Somatic PTPN11 mutations in childhood acute myeloid leukaemia. British journal of haematology 2005, 129(3):333-339. 
35. Grossmann KS, Rosário M, Birchmeier C, Birchmeier W: The tyrosine phosphatase Shp2 in development and cancer. Advances in cancer research 2010, 106:53-89.

36. Higashi H, Nakaya A, Tsutsumi R, Yokoyama K, Fujii $Y$, Ishikawa S, Higuchi M, Takahashi A, Kurashima $\mathrm{Y}$, Teishikata $\mathrm{Y}$ et al: Helicobacter pylori CagA Induces Ras-independent Morphogenetic Response through SHP-2 Recruitment and Activation. Journal of Biological Chemistry 2004, 279(17):17205-17216.

37. Frearson JA, Alexander DR: The phosphotyrosine phosphatase SHP-2 participates in a multimeric signaling complex and regulates T cell receptor (TCR) coupling to the Ras/mitogenactivated protein kinase (MAPK) pathway in Jurkat $\mathrm{T}$ cells. The Journal of experimental medicine 1998, 187(9):1417-1426.

38. Feng GS, Hui CC, Pawson T: SH2-containing phosphotyrosine phosphatase as a target of protein-tyrosine kinases. Science 1993, 259(5101):1607-1611.

39. Feng GS, Pawson T: Phosphotyrosine phosphatases with SH2 domains: regulators of signal transduction. Trends Genet 1994, 10(2):54-58.

40. Agazie $\mathrm{Y}$, Ischenko I, Hayman M: Concomitant activation of the PI3K-Akt and the Ras-ERK signaling pathways is essential for transformation by the V-SEA tyrosine kinase oncogene. Oncogene 2002, 21(5):697-707.

41. Agazie YM, Hayman MJ: Molecular mechanism for a role of SHP2 in epidermal growth factor receptor signaling. Molecular and cellular biology 2003, 23(21):7875-7886.

42. Agazie YM, Movilla N, Ischenko I, Hayman MJ: The phosphotyrosine phosphatase SHP2 is a critical mediator of transformation induced by the oncogenic fibroblast growth factor receptor 3. Oncogene 2003, 22(44):6909-6918.

43. Wu JH, Goswami R, Cai X, Exum ST, Huang X, Zhang L, Brian L, Premont RT, Peppel K, Freedman NJ: Regulation of the platelet-derived growth factor receptor-beta by $\mathrm{G}$ proteincoupled receptor kinase-5 in vascular smooth muscle cells involves the phosphatase Shp2. The Journal of biological chemistry 2006, 281(49):37758-37772.

44. Zhang SQ, Yang W, Kontaridis MI, Bivona TG, Wen G, Araki T, Luo J, Thompson JA, Schraven BL, Philips MR et al: Shp2 regulates SRC family kinase activity and Ras/Erk activation by controlling Csk recruitment. Molecular cell 2004, 13(3):341-355.

45. Zhou X, Agazie YM: Molecular mechanism for SHP2 in promoting HER2-induced signaling and transformation. The Journal of biological chemistry 2009, 284(18):12226-12234.

46. Zhou X, Y. M. Agazie: Molecular mechanism for SHP2 in promoting HER2-induced signaling and transformation. J Biol Chem 2009, [Epub ahead of print].

47. Hartman ZR, Schaller MD, Agazie YM: The tyrosine phosphatase SHP2 regulates focal adhesion kinase to promote EGF-induced lamellipodia persistence and cell migration. Molecular cancer research : MCR 2013.

48. Zhou X, Coad J, Ducatman B, Agazie YM: SHP2 is up-regulated in breast cancer cells and in infiltrating ductal carcinoma of the breast, implying its involvement in breast oncogenesis. Histopathology 2008, 53(4):389-402.

49. Muenst S, Obermann EC, Gao F, Oertli D, Viehl CT, Weber WP, Fleming T, Gillanders WE, Soysal SD: Src homology phosphotyrosyl phosphatase-2 expression is an independent negative prognostic factor in human breast cancer. Histopathology 2013, 63(1):74-82.

50. Zhou XD, Agazie YM: Inhibition of SHP2 leads to mesenchymal to epithelial transition in breast cancer cells. Cell death and differentiation 2008, 15(6):988-996.

51. Hartman ZR, Schaller MD, Agazie YM: The tyrosine phosphatase SHP2 regulates focal adhesion kinase to promote EGF-induced lamellipodia persistence and cell migration. Molecular cancer research : MCR 2013, 11(6):651-664. 
52. Zhao H, Agazie YM: Inhibition of SHP2 in basal-like and triple-negative breast cells induces basal-to-luminal transition, hormone dependency, and sensitivity to anti-hormone treatment. BMC cancer 2015, 15:109.

53. Matalkah F, Martin E, Zhao H, Agazie YM: SHP2 acts both upstream and downstream of multiple receptor tyrosine kinases to promote basal-like and triple-negative breast cancer. Breast cancer research : BCR 2016, 18(1):2.

54. Hollestelle A, Nagel JH, Smid M, Lam S, Elstrodt F, Wasielewski M, Ng SS, French PJ, Peeters JK, Rozendaal MJ et al: Distinct gene mutation profiles among luminal-type and basal-type breast cancer cell lines. Breast cancer research and treatment, 121(1):53-64.

55. Neve RM, Chin K, Fridlyand J, Yeh J, Baehner FL, Fevr T, Clark L, Bayani N, Coppe JP, Tong F et al: A collection of breast cancer cell lines for the study of functionally distinct cancer subtypes. Cancer cell 2006, 10(6):515-527.

56. O'Connor PM, Jackman J, Bae I, Myers TG, Fan S, Mutoh M, Scudiero DA, Monks A, Sausville EA, Weinstein JN et al: Characterization of the $p 53$ tumor suppressor pathway in cell lines of the National Cancer Institute anticancer drug screen and correlations with the growthinhibitory potency of 123 anticancer agents. Cancer research 1997, 57(19):4285-4300.

57. Filmus J, Pollak MN, Cailleau R, Buick RN: MDA-468, a human breast cancer cell line with a high number of epidermal growth factor (EGF) receptors, has an amplified EGF receptor gene and is growth inhibited by EGF. Biochemical and biophysical research communications 1985, 128(2):898-905.

58. Scherr M, Chaturvedi A, Battmer K, Dallmann I, Schultheis B, Ganser A, Eder M: Enhanced sensitivity to inhibition of SHP2, STAT5, and Gab2 expression in chronic myeloid leukemia (CML). Blood 2006, 107(8):3279-3287.

59. Engelmann K, Shen H, Finn OJ: MCF7 side population cells with characteristics of cancer stem/progenitor cells express the tumor antigen MUC1. Cancer Res 2008, 68(7):2419-2426.

60. Fillmore CM, Kuperwasser C: Human breast cancer cell lines contain stem-like cells that selfrenew, give rise to phenotypically diverse progeny and survive chemotherapy. Breast cancer research : BCR 2008, 10(2):R25.

61. Khoury T, Ademuyiwa FO, Chandrasekhar R, Jabbour M, Deleo A, Ferrone S, Wang Y, Wang X: Aldehyde dehydrogenase $1 \mathrm{~A} 1$ expression in breast cancer is associated with stage, triple negativity, and outcome to neoadjuvant chemotherapy. Modern pathology : an official journal of the United States and Canadian Academy of Pathology, Inc 2012, 25(3):388-397.

62. Yang L, Perez AA, Fujie S, Warden C, Li J, Wang Y, Yung B, Chen Y-R, Liu X, Zhang H et al: Wnt modulates MCL1 to control cell survival in triple negative breast cancer. BMC cancer 2014, 14:124-124.

63. Hadari YR, Kouhara H, Lax I, Schlessinger J: Binding of Shp2 Tyrosine Phosphatase to FRS2 Is Essential for Fibroblast Growth Factor-Induced PC12 Cell Differentiation. Molecular and Cellular Biology 1998, 18(7):3966-3973.

64. Ishida H, Kogaki S, Narita J, Ichimori H, Nawa N, Okada Y, Takahashi K, Ozono K: LEOPARDtype SHP2 mutant GIn510Glu attenuates cardiomyocyte differentiation and promotes cardiac hypertrophy via dysregulation of Akt/GSK-3beta/beta-catenin signaling. American journal of physiology Heart and circulatory physiology 2011, 301(4):H1531-1539.

65. Valenta T, Hausmann G, Basler K: The many faces and functions of beta-catenin. The EMBO journal 2012, 31(12):2714-2736.

66. Choi SH, Estaras C, Moresco JJ, Yates JR, 3rd, Jones KA: alpha-Catenin interacts with APC to regulate beta-catenin proteolysis and transcriptional repression of Wnt target genes. Genes \& development 2013, 27(22):2473-2488. 
67. Tan X, Apte U, Micsenyi A, Kotsagrelos E, Luo JH, Ranganathan S, Monga DK, Bell A, Michalopoulos GK, Monga SP: Epidermal growth factor receptor: a novel target of the Wnt/beta-catenin pathway in liver. Gastroenterology 2005, 129(1):285-302.

68. Tan X, Apte U, Micsenyi A, Kotsagrelos E, Luo J-H, Ranganathan S, Monga DK, Bell A, Michalopoulos GK, Monga SPS: Epidermal growth factor receptor: a novel target of the Wnt/beta-catenin pathway in liver. Gastroenterology 2005, 129(1):285-302.

69. Lim SO, Li CW, Xia W, Lee HH, Chang SS, Shen J, Hsu JL, Raftery D, Djukovic D, Gu H et al: EGFR signaling enhances aerobic glycolysis in triple negative breast cancer cells to promote tumor growth and immune escape. Cancer Res 2016.

70. Hartman Z, Zhao H, Agazie YM: HER2 stabilizes EGFR and itself by altering autophosphorylation patterns in a manner that overcomes regulatory mechanisms and promotes proliferative and transformation signaling. Oncogene 2013, 32(35):4169-4180.

71. Martin V, Botta F, Zanellato E, Molinari F, Crippa S, Mazzucchelli L, Frattini M: Molecular characterization of EGFR and EGFR-downstream pathways in triple negative breast carcinomas with basal like features. Histology and histopathology 2012, 27(6):785-792.

72. Gilles C, Polette M, Mestdagt M, Nawrocki-Raby B, Ruggeri P, Birembaut P, Foidart J-M: Transactivation of vimentin by beta-catenin in human breast cancer cells. Cancer research 2003, 63(10):2658-2664.

73. Li H, Sekine M, Tung N, Avraham HK: Wild-type BRCA1, but not mutated BRCA1, regulates the expression of the nuclear form of beta-catenin. Molecular cancer research : MCR 2010, 8(3):407-420.

74. Khramtsov Al, Khramtsova GF, Tretiakova M, Huo D, Olopade OI, Goss KH: Wnt/beta-catenin pathway activation is enriched in basal-like breast cancers and predicts poor outcome. The American journal of pathology 2010, 176(6):2911-2920.

75. Wend P, Runke S, Wend K, Anchondo B, Yesayan M, Jardon M, Hardie N, Loddenkemper C, Ulasov I, Lesniak MS et al: WNT10B/ $\beta$-catenin signalling induces HMGA2 and proliferation in metastatic triple-negative breast cancer. EMBO molecular medicine 2013, 5(2):264-279.

76. Dey N, Barwick BG, Moreno CS, Ordanic-Kodani M, Chen Z, Oprea-llies G, Tang W, Catzavelos C, Kerstann KF, Sledge GW et al: Wnt signaling in triple negative breast cancer is associated with metastasis. BMC cancer 2013, 13:537-537. 